\title{
On future household structure
}

\author{
Juha Alho \\ Department of Computer Science and Statistics \\ University of Joensuu \\ Finland \\ juha.alho@joensuu.fi
}

\author{
Nico Keilman \\ Department of Economics \\ University of Oslo \\ Norway \\ nico.keilman@econ.uio.no
}

February 2009

\section{Summary}

We have developed a method for computing probabilistic household forecasts, which quantifies uncertainty in the future number of households of various types in a country. A probabilistic household forecast helps policy makers, planners, and other forecast users in the fields of housing, energy, social security etc., in taking appropriate decisions, because some household variables are more uncertain than others. Deterministic forecasts traditionally do not quantify uncertainty. We have applied the method to data from Norway. We find that predictions of future numbers of married couples, cohabiting couples, and one-person households are more certain than those of lone parents and other private households.

Our method builds on an existing method for computing probabilistic population forecasts, combining such a forecast with a random breakdown of the population according to household position (single, cohabiting, living with spouse, living alone etc.). In this application, uncertainty in the total numbers of households of different types derives primarily from random shares, rather than uncertain future population size. A similar method could be applied to obtain probabilistic forecasts for other divisions of the population, such as household size, health or disability status, region of residence, labour market status, etc.

Key words: household forecast, probabilistic forecast, population forecast, random shares, Norway 


\section{Introduction}

Knowledge about the future number of households, and their composition, is important for policy purposes. The amount of support needed by the elderly depends on the numbers living alone, for example (Grundy 2001; Glaser et al. 2003). Housing planners use forecasts of household size to anticipate changes in the demand of dwellings with elevators and wheel-chair access (Holmberg 1987, King 1999, Muller et al. 1999). A recent environmental concern stems from the increasing number of small households. Household members share space, home furnishings, transportation, and energy, leading to significant economies of scale. For instance, members of two-person households in the United States in 1993-94 used 17\% less energy per person than one-person households did (O’Neill and Chen 2002). Thus, even when the population remains constant, more small households imply a larger demand for resources.

There are many possible future household developments for a given population, but some of these are more likely than others. As opposed to a deterministic forecast, which predicts only one number (or perhaps just a few; see below) for a certain year, a probabilistic forecast tells us how likely it is that future household numbers will be within a certain range. For instance, the results we obtain in Section 4 imply a 50 per cent chance for the number of private households in Norway to be between 2.51 and 2.69 million in 2030, up from an observed 2.03 million in 2002. Information of this kind allows policy makers, planners, and other forecast users in the fields of housing, energy, social security etc. to take appropriate decisions, because some household variables are more uncertain than others. It also guides them once actual developments start to deviate from the most likely path. New actions or updated plans are unnecessary as long as developments remain close to the predicted path. Deterministic forecasts traditionally deal with forecast uncertainty by formulating alternative scenarios, usually in terms of a high and a low trajectory for some key input parameter, in addition to a most likely trajectory (Jiang and O'Neill 2006). The drawback is that uncertainty is not quantified, and hence the user does not know how likely it is that the high trajectory will materialize, instead of the most likely one. Moreover, the results are not plausible from a statistical point of view, as they implicitly assume perfect correlation across age, time, and household type (Lee 1999, Alho et al. 2008).

The purpose of this paper is to show how statistical forecasting methods and existing software can be used to produce a probabilistic household forecast, thus avoiding the drawbacks of a deterministic approach. Methods for computing probabilistic population forecasts have become well established in the past two decades. The tradition goes back to Leo Törnqvist (1949), who probably was the first one to integrate probabilistic thinking in population forecasting. Examples include probabilistic population forecasts for the United States, Austria, Finland, the Netherlands, Norway by Lee and Tuljapurkar (1994), Lutz and Scherbov (1998), Alho (1998); De Beer and Alders (1999), and Keilman et al. (2002) respectively, for 18 European countries (the old EU15-countries plus Norway, Iceland and Switzerland) 
by Alho et al. (2006), for major world regions by Lutz et al $(1996,2001)$, and for all countries in the world in the US National Research Council Report (NRC 2000). Deterministic household forecasts have a somewhat longer tradition (US National Resources Planning Committee 1938; United Nations 1973; Keilman et al. 1988), but few scholars have attempted to compute a probabilistic household forecast.

Alders $(1999,2001)$ combined a probabilistic population forecast with random shares that distributed the population probabilistically over six household positions: individuals could either live as a child with parents, live alone, live with a partner, as a lone parent, in an institution, or belong to an other category. For instance, Alders computed a predictive distribution for the number of lone mothers aged 40 in 2015 as the product of two random variables, namely the number of women aged 40 in 2015 and the share of those women who live as a lone mother. Expected values for population variables and shares for specific household types were obtained from observed time series, but uncertainty distributions assumed for both were based on intuitive reasoning, and correlations across age, sex, and time were disregarded. Scherbov and Ediev (2007) combined a probabilistic population forecast for the population broken down by age and sex with random headship rates. In demography, a headship rate reflects the proportion of the population that is the head of the household, for a given combination of age and sex (United Nations 1973; Jiang and O’Neill 2004). Like Alders, Scherbov and Ediev based a large part of their uncertainty distributions on intuition. In contrast, our contribution is to show how uncertainty in the forecast of the shares that distribute the population over several household positions can be modelled as a stochastic process, the parameters of which can be estimated from past data.

We discuss conceptual issues in Section 2. Perhaps surprisingly, there is no general agreement on the concepts of household and family. We give our working definitions and discuss measurement problems. In Section 3, we briefly describe deterministic and probabilistic forecasts of households and population, and present our model that is based on random shares. Section 4 gives an empirical application for Norway.

\section{Conceptual issues}

2.1 Defining household and family

Durkheim's classic notion of a "nuclear family" refers to a married couple and their dependent children, living together but apart from other kin (Moen and Forest 1999; Hoffmann-Nowotny 1987; Smith 1968). During the post World War II period, the notion of a family has broadened to include a range of forms, but new debates have arisen (Settles 1999). For instance, should a cohabiting or a same-sex couple be considered as a family? Does the family definition also cover lone parents? Such issues are important when families are viewed from the perspective of the special rights and obligations family members have with each other (Lenoir 2007). 
As our interest is in the sharing of dwellings, we will bypass the thorny issues referred to above, and consider a less value-laden concept of a household. A household consists of all persons who live in the same dwelling, independently of how they view their family relationships with each other. Thus, a household may include just one person, or several unrelated individuals (e.g., students). These definitions are compatible with the so-called "dwelling definition" of the Conference of European Statisticians (2006). With this approach we could logically take dwellings, or households, as our statistical units of observations, and analyse how the number of households of different types (for instance one-person households, couple households, one-parent family households) develop over time. However, opting for the household as the unit of analysis would lead to conceptual problems. The moment at which a household is formed or dissolved is not always well defined, nor is the household membership always clear. Rules may be set up, for instance that two households, when observed at two different points in time, are the same as soon as they have the same household head. But rules of this kind are largely arbitrary, and moreover, may have strong impact on the results (McMillan and Herriott 1985; Keilman and Keyfitz 1988). Data on an individual person, such as date of birth, death, marriage, divorce or separation, home-leaving etc., provide a firmer basis, once the individuals' household positions have been defined. This is not without problems either, but the issues appear to be solvable. We shall now address these.

A fairly generally recommended practice is to distinguish the following positions in a private household (Moen and Forrest 1999). (1) Child refers to a blood, step- or adopted son or daughter younger than 25 years of age (but regardless of marital status) who lives in the household of at least one of the parents, and who has no partner or own child(ren) in the same household. (2) A cohabiting couple (i.e. partners living in a consensual union) is a couple that has a marriage-like relationship, irrespective of the partners' sexes. Cohabiting persons can have any marital status (including married; in that case they are legally married to different partners, who live elsewhere). (3) The category of married couples consists of those who are currently married and live together with the spouse. (4) A lone parent lives together with one or more children as defined above, but without a spouse or cohabiting partner. (5) An adult may live alone. (6) Young adults aged 25 or over, as well as persons younger than 25 with a partner or an own child, who live with their parent(s) belong to the category other. The latter category also includes persons who live in a multi-person household but who have no relationship (parent-child, or partner in consensual or marital union) to the other household members.

Knowing the household positions of the household members, the household type can be deduced: a private household may be a married couple household, a cohabiting couple household, a lone parent household, a one-person household, or a household of type "other". Compared to Alders' household 
forecast, our forecast distinguishes married couples from cohabiting couples, but (due to data limitations) we ignore institutional households.

\subsection{Some measurement problems}

It is not always possible to elicit reliable information on household position in surveys or censuses. We point out four recognized sources of potential variation.

1. The notion of "living in the same dwelling" is based on an individual's place of usual residence. In our Norwegian application we will use data from the Census and the Survey of Living Conditions (SLC). The SLC is a panel survey with annual waves in the spring of each year since 1997; see Normann (2004). The Census is based on the de jure definition, whereas SLC uses a de facto concept that includes the requirement of "common housekeeping". These differ, in particular, for young adults. For example, a person who leaves the parental household will not be officially registered at the new address, unless he or she marries, has a child, or receives the major part of his or her income from labour. Similarly, when elderly persons move back and forth between a private dwelling and an institution because of health problems, it is not clear how their place of usual residence is decided. 2. The distinction between private and institutional households is not clear cut in intermediate forms such as assisted living etc.

3. The notion of cohabiting couple living in a "marriage-like relationship" leaves room for subjective interpretations, which may change over time, and differ between the partners.

4. A lone parent who starts cohabiting may still be classified as a lone parent, if the new partner does not take parental responsibility for the children.

\section{Method}

\subsection{Outline}

We start with a non-technical outline of our approach, while Sections 3.2-3.5 contain formal details. We build on an existing probabilistic forecast for the population of Norway. Similar to a deterministic population forecast, a probabilistic population forecast is based upon the "book keeping" identity

$$
\begin{aligned}
\operatorname{population}(t+1)= & \operatorname{population}(t)+\operatorname{births}(\operatorname{during} t)-\text { deaths }(\text { during } t)+\text { immigration }(\text { during } t)- \\
& \text { emigration }(\text { during } t) .
\end{aligned}
$$

In practice, updates of this kind are done for men and women by age. In a deterministic population forecast, one needs to specify age specific fertility rates for women and mortality rates for women and men, for all future years of interest. These are used to calculate numbers of births and deaths. Migration is usually specified as net migration in absolute numbers, the survivors of which are added to the population at time $t$. Starting from a known population by age and sex at some initial time $t=0$ - the so-called jump-off population - this method is used recursively to keep track of the resulting changes in 
population, by age and sex. Stochastic (or probabilistic) population forecasts are similar, but in this case future fertility and mortality rates and net migration numbers are considered as random variables (e.g. Alho and Spencer, 2005). Simulation is used to carry out the propagation of uncertainty, from the rates to future population numbers. A joint distribution derived in this manner for the future demographic variables can be called a predictive distribution. In other words, it is the probability distribution of the future demographic variables, conditional on what was known at the time when the forecast was made.

For the 18 European countries mentioned in Section 1, the results of such probabilistic population forecasts are available as simulated predictive distributions for the numbers of men and women by fiveyear age group for the period 2010-2050, at ten-year intervals. The predictive distribution of each population variable is given in the form of 3000 simulated values; see www.stat.fi/tup/euupe/index en.html. We use simulation results for Norway from this source. Next, given age, sex, and time, we assume that the population will have one of the six mutually exclusive household positions defined in Section 2.1, and we define a set of six shares, the sum of which equals one. We predict the shares as a function of age, sex, and time. This requires specifying their predictive distributions. We assume a particular statistical model for each share, which defines its distribution at one point in time, as well as its development over time. The parameters of the model are the expected value of the share and its variance. We derive the shares' expected values from a deterministic household forecast. The variance of each share reflects the deviation from its expected values, in other words, the variance is a measure for forecast errors in the shares. Empirical information for forecast errors is derived from the errors of a household forecast, prepared in the early 1990s and covering the years 1990-2020. We assume that the errors in the future are not smaller. Finally, we compute a forecast for the number of persons in a given household position as the product of two random variables, namely the predicted population and the predicted share for that household position.

In practice, we draw 3000 values from the predictive distribution of the shares for each combination of age, sex, and household position, for the years 2010, 2020, and 2030, and combine them with 3000 simulated values for the population numbers by age and sex. Given predicted numbers of persons in all six household positions in a certain year, predicted numbers of households of various types can be derived.

\subsection{Notation}

We will write $V(j, x, s, t)$ for the number of people in household position $j=1,2, \ldots, 6$ who are in age $x=$ $0,1, \ldots, \omega ; \operatorname{sex} s=1$ for males and $s=2$ for females; at time $t=0,1,2, \ldots$ Aggregating over position, we get the population $W(x, s, t)=\Sigma_{j} V(j, x, s, t)$ of age $x$ and sex $s$ at time $t$. The share of household position $j$ is $\rho(j, x, s, t)=V(j, x, s, t) / W(x, s, t)$. We have a probabilistic forecast for the population $W(x, s, t)$ available. 
We will specify a predictive distribution for the shares $\rho(j, x, s, t)$ for future years. Then, the product $\rho(j, x, s, t) W(x, s, t)$ will yield a predictive distribution for $V(j, x, s, t)$.

\subsection{Stochastic forecast of population}

The stochastic population forecast of Norway (the random variable $W(x, s, t)$ ) was taken from the project "Uncertain Population of Europe" (UPE), which gives predictive distributions of the population by sex and age in 18 European countries for the period 2004-2050. A general description of the results is available in Alho et al. (2006), while Alders et al. (2007) and Alho et al. (2008) discuss the assumptions made. Simulation results are posted at http://www.stat.fi/tup/euupe/no11 results nor.html. For Norway, a population of 5.26 million is expected for 2030, very close to the 5.37 million of Statistics Norway's medium growth variant, made in 2005 (http://www.ssb.no/emner/02/03/folkfram/tab-2005-12-1501.html). The 80 per cent prediction interval is $[4.90,5.65]$ million. An 80 per cent interval for the share of the $65+$ population is $[19.5,23.3]$ per cent - in 2008 it was 14.7 per cent.

\subsection{Point predictions of household shares}

The point predictions (or expected values) of the household shares were derived from an updated deterministic household forecast for Norway (see Keilman and Brunborg 1995 for the original household forecast). This resulted in point predictions $\hat{\rho}(j, x, s, t)$ for the period 2002-2032. We used the program LIPRO ("Lifestyle projections") version 4.0 to compute the household forecast. LIPRO (see http://www.nidi.knaw.nl/en/projects/270101/ and Van Imhoff and Keilman 1991) is based on the methodology of multi-state demography, but includes several extensions to solve the particular problems of household modelling.

\subsubsection{Population structure}

The number and types of household position that we selected are a compromise between conflicting arguments. On the one hand, we want to have many household positions, in order to provide the user of the forecast with detailed results. But the available data restrict the possibilities one has to a considerable extent. As opposed to the random shares, for which we only distinguish six household positions (see Section 2.1) we had enough data for the deterministic household forecast to work with a slightly more detailed classification. We have used the following nine household positions for individuals:

1. dependent child living with one or both parents.

2. living in a consensual union without dependent children.

3. living in a consensual union with dependent children.

4. living with a spouse without dependent children. 
5. living with a spouse and dependent children.

6. person living in a one-person household.

7. single mother or father.

8. living in a private household, but not in any of the positions 1-7.

9. living in an institution for the elderly.

The institutionalized population was restricted to ages 65 and older. Compared to the six household positions for which we will specify uncertainty distributions, the nine positions listed here imply full coverage of the population, both in private and in institutional households. Also, we distinguish cohabiting couples and married couples with and without dependent children in their homes. The reason is that childless couples have a different childbearing behaviour than those with one or more children. Given the point predictions for the nine shares, those for the six shares are easily obtained by combining those for cohabiting or married persons with and without children, and conditioning upon being a member of a private household.

LIPRO implements a multi-state demographic model that focuses on flows between the states. Multistate projections are inherently more complex than single-state projections. In particular, they require more extensive data. We will here sketch the main aspects of the LIPRO calculations and refer to Van Imhoff and Keilman (1991) for the full details.

Let $\boldsymbol{V}(t)$ be a row vector of population counts at exact time t. We use five-year age-groups $0-4,5-9, \ldots$, $85-89,90+$. Their number is 19 , and we will write $\boldsymbol{V}(t)=(\boldsymbol{V}(0, t), \ldots, \boldsymbol{V}(18, t))$. We keep track of females and males separately, so $\boldsymbol{V}(x, t)=(\boldsymbol{V}(x, \mathrm{~F}, t), \boldsymbol{V}(x, \mathrm{M}, t))$ for each age-group $x=0, \ldots, 18$. There are nine household positions, so for example, $\boldsymbol{V}(x, \mathrm{~F}, t)=(V(1, x, \mathrm{~F}, t), \ldots, V(9, \mathrm{~F}, x, t))$, where $V(j, x, \mathrm{~F}, t)$ is the number of females in position $j$, in age $x$, at time $t$. Thus, $\boldsymbol{V}(t)$ has a total of $19 \times 2 \times 9=342$ elements.

To describe population change, suppose first that there is no external migration. Consonant with age grouping, we take a unit of time to correspond to five calendar years. Consider survival from exact time $t$ to exact time $t+1$ for women. This can be expressed as $\boldsymbol{V}(x+1, \mathrm{~F}, t+1)=\boldsymbol{V}(x, \mathrm{~F}, t) \boldsymbol{S}(x, \mathrm{~F}, t)$, where $\boldsymbol{S}(x, \mathrm{~F}, t)$ is a $9 \times 9$ matrix of origin-destination specific survival probabilities for women from age-group $x$ to age-group $x+1$. Specifically, row $j$ of $\boldsymbol{S}(x, \mathrm{~F}, t)$ gives the proportions surviving to positions $k=1, \ldots$, 9 , for women who are in position $j$ at time $t$. Since the proportions reflect both mortality and position transitions, the row sums are typically less than one. For forecasting purposes the probabilities in $\boldsymbol{S}(x, \mathrm{~F}, t)$ could be specified directly, but as empirical data often come in the form of occurrenceexposure rates (equivalent to hazard rates in survival analysis) rather than proportions, LIPRO expects as inputs age and sex-specific occurrence-exposure rates from one household position to another. It is well-known (e.g. Schoen 1988) that if the rates are equal in all ages belonging to age-group $x$, and they 
remain constant from exact time $t$ to exact time $t+1$, then $\boldsymbol{S}(x, \mathrm{~F}, t)$ is given by an exponential function of a matrix argument. We skip the details, but note that the argument matrix is a function of the occurrence-exposure rates that are specific for age, sex, and household position, including the death rates. Survival calculations in LIPRO are based on this assumption of time-constant rates, which, of course, is an approximation to how things are in reality (for a discussion of alternatives, see Alho and Spencer 2005).

Consider births. As is usual in demography, LIPRO attributes births to women only. The child-bearing ages in our application are $15-49$, corresponding to $x=3, \ldots, 9$. LIPRO expects a vector of age and household position-specific (annual) birth rates $\boldsymbol{b}(x, t)$ that are assumed to be the same for all women in an age-group. Being analytical, the exponential solution to survival calculations gives us not only $\boldsymbol{V}(x+1, \mathrm{~F}, t+1)$, but $\boldsymbol{V}\left(x+t^{\prime}, \mathrm{F}, t+t^{\prime}\right)$ for any $0<t^{\prime}<1$. These values can be analytically integrated over $t^{\prime}$ to get a vector with person-years by age and household position, $\boldsymbol{K}(x, \mathrm{~F}, t)$, during the period $(t, t+1)$. LIPRO uses this formulation. Multiplying $\boldsymbol{K}(x, \mathrm{~F}, t)$ elementwise by $\boldsymbol{b}(x, t)$ yields a vector of births, by household position, in age-group $x$, that are expected during period from $t$ to $t+1$. LIPRO survives these to exact time $t+1$ using an exponential survivorship matrix of the type discussed above. Only now survival time is 0.5 time units, corresponding to 2.5 calendar years. This is an approximation that is frequently used in demography.

The description of external migration is logically difficult, because in-migration does not have a natural "population-at-risk". In this respect there is no difference between multi-state and single-state projections. In applications, in which the level of migration is small relative to the populations of interest, a practical expedient is to express both in-migration and out-migration in terms of absolute numbers. But, as soon as this decision is made, it becomes clear that it is not necessary to keep track of in and out-migration separately. To see this, consider a woman entering into household position $j$, in age-group $x$, at some time $t+t^{\prime}, 0<t^{\prime}<1$. We can think of her as starting a sub-population of her own that survives to different household positions and renews itself by births, until $t+1$ and beyond, as described above. On the other hand, should a similar woman leave the population of interest at $t+t^{\prime}$, we should obviously subtract the sub-population she contributes after $t+t^{\prime}$. From these considerations it is clear that it is simply the difference of in-migration and out-migration at any given time that determines the effect of external migration on the future evolution of the population. LIPRO expects as input age, sex, and position-specific net-migration numbers that are assumed to be uniformly distributed over the interval $(t, t+1)$, and computes their net effect based on the principles laid out above for survival and births.

The model is driven forward by assumptions, for each time interval, on net immigration by age, sex, and household position, on occurrence-exposure rates for household events and mortality, and on birth 
rates; see below. To specify the jump-off population $\left(\boldsymbol{V}_{\mathbf{0}}\right)$ we used data from the Population and Housing Census of Norway, 3 November 2001, and assumed that the data would apply to 1 January 2002. Readers interested in the census may consult Statistics Norway's web site on this topic (in English) at http://www.ssb.no/english/subjects/02/01/fob2001_en/ .

\subsubsection{Events}

For the events, consider first the eight positions for private households. There are 7 x $8=56$ possibilities for change of position, but not all are logically possible. For instance, a person cannot change directly from "cohabiting, no children" to "married, with children". We estimated occurrenceexposure rates for changes of private household position from the Survey of Living Conditions (SLC) using data from 1997-2002, for ages 16-79. See Normann (2004) for a technical description of the SLC. In 1997, the sample size was approximately 5000. We deduced household events from changes in reported positions in consecutive interviews. We discarded information about two or more household events in one calendar year. This occurred rarely. Similarly, due to both left and right censoring, a small number of events could not be uniquely classified. Added over all five calendar years, we obtained 3,645 events for 27 types of positional change, and 22,462 years of exposure. The occurrenceexposure rates are specific for five-year age groups, private household position, and sex. Data on entries into and exits from institutional households are extremely scarce. We have used the entry rates and exit rates employed in the previous household forecast of Keilman and Brunborg (1995).

Birth rates by five-year age-group and household position of the mother were taken from the previous household forecast and adjusted proportionally to match the numbers that Statistics Norway had registered for 2002-2006. Death rates by five-year age-group, sex and household position were estimated based on deaths and exposure times by marital status, age, and sex for the years 1995-99, extracted from the Norwegian population registers. Mortality data by marital status for Norway are not available for more recent years. We applied the death rates of the "currently married" to household positions "cohabiting" or "married"; death rates of the never married to persons with household position "child", "living alone", or "other"; and death rates of the divorced to "lone parents". Since individuals who live in an institution have higher mortality than those who live in private households, death rates for the institutionalized were assumed twice as large as those of the never married (given age and sex).

International migration was specified as net immigration in absolute numbers. The level of net immigration for the years 2002-2006 was taken from data available from the population registers, and that for later years from Statistics Norway's population forecast; see below. Its distribution by age, sex and household position was borrowed from the previous household forecast. 


\subsubsection{Consistency}

In the LIPRO formulation, the units of analysis are individuals, and household statuses are viewed as their characteristics. This opens up the possibility of inconsistency between the attributes (Van Imhoff and Keilman 1991, Van Imhoff 1992). We defined a number of consistency relations for events experienced by members of the same household, namely for marriage of non-cohabiting partners and of cohabitees, for couple dissolution, and for events experienced by children and their parents. For example, the number of non-cohabiting men who marry during a certain period has to be equal to the number of non-cohabiting women who marry during that period. Also, the number of men who live with a cohabitee and who experience the exit of the last child (in other words, a change from position "cohabiting, with children" to position "cohabiting, no children") must be equal to the number of cohabiting women who experience the same event. LIPRO adjusted the parameter values for these household events in such a way that all relationships were fulfilled. We also constrained total numbers of births, deaths, and net immigration to corresponding numbers taken from observed population data for the years 2002-2006, and from the Medium Variant of Statistics Norway's 2005-based population forecast; see http://www.ssb.no/emner/02/03/folkfram/arkiv/. (Statistics Norway published a new population forecast in May 2008, but we were unable to include that in the present analyses.) Finally, we constrained the total population living in an institution to 41,000 , which is the level observed in the years 2003, 2004, and 2005. Based on the consistent events for household formation, household dissolution, births, deaths, and net immigration, LIPRO used book-keeping equations to update the population by age, sex, and household position from one point in time to the next. For instance, the number of married women aged 30-34 on 1 January 2007 was calculated as the corresponding number for ages 25-29 five years earlier, plus all newly married women and immigrating married women of that age group during 2002-2006, minus all women of that age group who experienced divorce, separation, or death during 2002-2006.

Apart from adjustments for consistency, parameters for household events were assumed constant over the forecast period, because the possible trends visible in our data were erratic. Thus, the point forecast of shares is equivalent to applying multi-state life table transition probabilities to the jump-off population.

\subsubsection{Point forecasts for the shares}

We computed a deterministic household forecast for men and women in five-year age groups in nine household positions for the years 2007, 2012, ..., 2032 (1 January), and derived point forecasts $\hat{\rho}(j, x, s, t)$. In terms of total population, the predicted number is 5.47 million in 2032. This result agrees quite well with the corresponding number predicted by Statistics Norway in its 2005-based 
population forecast, which is 5.43 million. The two numbers are close, as expected, because numbers of births, deaths, and net immigrations for the period 2002-2032 were constrained to be equal between the two forecasts; see Section 3.4 above. The remaining small difference is due to different jump-off populations. Since consistency for numbers of births, deaths, and net immigrations was not specific for age groups, the age structure that we predict is different from that of Statistics Norway. For example, for the year 2032 we find predicted shares in age groups 0-19, 20-64, and 65+ equal to 23, 56, and 22 per cent, respectively. Statistics Norway predicted 28, 52, and 20 per cent, respectively.

Figure 1 plots the marginal point forecasts for the shares of eight private household positions, irrespective of age and sex. The year 1990 (Census information) has been added for reference. The figure shows a continuation of changes in household and family structures that have gone on for several decades. It becomes increasingly more likely for Norwegian men and women to live alone or in consensual union, and less likely to live with a spouse and children. Data before 1990 comparable to those plotted in Figure 1 are not as detailed as current data, but some comparisons can be made. For instance, while seven per cent of the population lived alone in 1970, the proportion had increased to ten per cent in 1980 and 14 per cent in 1990 (Statistics Norway 2000, Table 1.3). Our forecast gives 20 per cent in 2032. In 1980, 31 per cent of Norwegian households consisted of a married couple with one or more children; the share was 23 per cent in 1990, and a mere 16 per cent in 2001 . The result for 2032 in Figure 1 is six per cent. In the three years 1980, 1990, and 2001, cohabiting couples with children made up one, three, and five per cent of all households, respectively; see http://www.ssb.no/english/subjects/02/01/20/familie_en/tab-2008-04-03-03-en.html. Our point prediction for 2032 is six per cent. In 1977, only twelve per cent of women aged 20-24 lived in cohabitation. Nowadays, the proportion is roughly one-third as measured by interview-based survey data (http://www.ssb.no/english/subjects/02/01/20/samboer en/tab-2008-04-17-01-en.html ), and slightly over one-sixth according to Census data. (The difference is explained by different definitions of an individual's place of residence across data sources; see the discussion in Section 2.) Our forecast with a jump-off population based on Census data - predicts a value of 23 per cent in 2032 for this share.

Point forecasts for the shares of women who live alone or with their marital spouse are plotted in Figures 2 and 3. Note that elderly women in Norway are less likely to live alone in the future, and more likely to live with their husbands. The same trend applies to shares of elderly men. To a large extent, this is due to improved longevity, but also to steeper increases in life expectancy for men than for women (Meslé 2004). A second important factor is the behaviour of cohorts born in the 1930s and 1940s. These cohorts were more likely to marry than older cohorts, who suffered from the economic crisis in the 1930s and the Second World War (Keilman and Christiansen 2008). 
To estimate the level of uncertainty one might expect in a new forecast of shares, we computed empirical errors in the shares $\hat{\rho}(j, x, s, t)$ from the deterministic forecast of Keilman and Brunborg (1995), with jump-off time 31 December 1990. We analysed six predicted shares for child (CHLD), cohabiting $(\mathrm{COH})$, living with spouse (MAR), living alone (SIN0), living as single parent together with one or more children $(\mathrm{SIN}+)$, and other $(\mathrm{OTH})$. The abbreviations denote individual household positions, and will be used later. The shares were evaluated against estimated shares from the 1997wave and the 2002-wave of the SLC, and data from the Census on 3 November 2001. As opposed to the deterministic household forecast in Section 3.4, we have not distinguished childless married or cohabiting couples from those who live with children, because the Census tables do not give that information. The six shares add up to one. Hence we excluded persons in institutional households, for reasons mentioned in Section 2.2. Possible consequences of this decision are briefly discussed in Section 4 below.

Figures 4-6 compare, for cohabiting, married, and living alone, predicted shares to the observed shares. The forecast predicted too few young cohabitants (Figure 4) and young adults living alone (Figure 6), as opposed to too many children living with their parents. Clearly, the age-pattern of the forecast tracks better the census figures than those of the SLC. We suspect that the difference is related to the way respondents have interpreted their household position in the survey as compared to the census. There is evidence that errors increase over time.

The group "other" consists primarily of adults in ages 25-30, who live with their parents, or of unrelated persons who share a dwelling. Thus, the dividing line between statuses "child" and "other" is unclear.

\subsection{Modelling errors in the forecasts of shares}

We computed errors in share forecasts for three dates (SLC waves of Spring 1997 and Spring 2002, and the Census of November 2001), two sexes, six household positions, and 16 five-year age groups 15-19, $20-24, \ldots, 90+$. This makes a total of 576 possible errors. In practice, we analysed 385 observations of non-zero shares for the three time points, by age and sex: 12 for "child", 81 both for "cohabiting" and for "married", 88 for "living alone", 49 for "lone parent", and 74 for "other". We disregarded persons recorded as "child" who were age 25 or older, and "lone parents" age 60 or more. It quickly turned out that the error patterns in SLC data were highly erratic. However, the survey data were useful in helping us to check that a random walk model is an acceptable approximation for the increase over time in forecast error (a perfect random walk would have implied a linear increase with time in the variance of the forecast error; e.g. see Alho and Spencer 2005). For instance, in a preliminary stage we analysed a multinomial logit transformation for the six shares with the position "living alone" as the reference 
category. Write the six shares as $p_{1}, p_{2}, \ldots, p_{6}$, with $p_{1}$ the share for "living alone", where we suppress indices for time, age, and sex. The sum of all shares equals one. The multinomial logit transformation is $q_{\mathrm{i}}=\ln \left(p_{\mathrm{i}} / p_{1}\right), \mathrm{i}=2,3, \ldots, 6$. We computed errors in predicted values of $q_{\mathrm{i}}$ according to the old household forecast by comparing predicted $q_{i}$-values with observed $q_{i}$-values from the Census and the two SLC waves. For each of the five household positions and each of the three time points we computed the mean squared error (MSE) in $q_{i}$ across age and sex. Table 1 gives MSE-values, which can be interpreted as conservative estimates of error variances (since the mean squared error of a forecast equals variance of forecast error plus forecast bias squared). In computing the values in Table 1, we have subtracted sampling error in 1997 and 2002 from total forecast error (details available from the second author upon request).

Table 1. Mean squared errors in predicted shares for five household positions (multinomially logit transformed, with household position "living alone" as reference category)

\begin{tabular}{lccccc}
\hline & CHLD & COH & MAR & OTHR & SIN+ \\
\hline Survey of Living Conditions & & & & & \\
Spring 1997 & 0.779 & 0.231 & 0.199 & 0.601 & 2.422 \\
Census November 2001 & 1.324 & 0.379 & 0.278 & 0.725 & 1.620 \\
Survey of Living Conditions & & & & & \\
Spring 2002 & 1.868 & 0.630 & 0.537 & 1.488 & 1.776 \\
\hline
\end{tabular}

Abbreviations for household positions: CHLD: child living with parents; $\mathrm{COH}$ : living in consensual union; MAR: married, living with spouse; OTHR: living in other private household; SIN+: lone parent.

For all household positions except "lone parent", the MSE-values in Table 1 increase between the three dates, albeit somewhat irregularly. For instance, during the period from the Spring of 1997 to November 2001 (approximately four years), the MSE's of household positions COH, MAR, and OTHR increase much slower than they do during the period from November 2001 to the Spring of 2002 (about six months). Because of the irregularity in the SLC errors noted earlier, the estimation of the variances of forecast error was based on the census data alone.

For modelling random evolution of the shares, a logit transformation was first applied. Based on Figures 4-6, we opted for a tree-like structure, or a variant of continuing fractions, that led to four types of fraction to be modelled (all specific for age, sex, and time),

(a) total share of MAR and SIN0,

(b) relative share of MAR out of MAR and SIN0,

(c) relative share of $\mathrm{COH}$ out of total share of $\mathrm{COH}, \mathrm{SIN}+, \mathrm{CHLD}$, and OTHR,

(d) relative share of CHLD and OTHR out of total share of CHLD, OTHR, and SIN+.

Temporarily suppressing indices for age and sex, denote the combined household positions of MAR and SIN0 (type (a) above) as $j=1$, define the logit transform of the share $\rho(1, t)$ as 
$\xi(1, t)=\ln \{\rho(1, t) /[1-\rho(1, t)]\}$,

and write the observed $\xi$ as the sum of the predicted value and an error term:

$\xi(1, t)=\hat{\xi}(1, t)+e_{\xi}(1, t)$. Here $\hat{\xi}(1, t)$ denotes the logit transform of the point prediction $\hat{\rho}(1, t)$ in the old household forecast. Next, construct a univariate random walk for $e_{\xi}(1, t)$. In other words, assume the following model

$e_{\xi}(1, t)=\varepsilon(1,1)+\varepsilon(1,2)+\ldots+\varepsilon(1, t)$

where $\varepsilon(1, t)$ is an i.i.d. sequence of random terms with zero expectation and time-constant variance to be specified. Next, take the conditional share of MAR out of MAR and SIN0 (type (b) above), compute the logit transformed value of that share, and construct a second univariate random walk in the logit scale. Continue this way with the empirical errors for the remaining two conditional shares. By construction, the four univariate random walks in the logit scale are statistically independent.

We used observed and predicted values of the conditional shares, computed empirical forecast errors for each share, and estimated the variances $\operatorname{Var}[\varepsilon(j, t)]$ as the Mean Squared Error in the forecast for each of the four shares, assuming that those variances are independent of sex and age. For the four shares listed under (a)-(d) above, the estimates turned out to be 0.090, 0.098, 0.129, and 0.321 respectively. We estimated the correlation between the sexes Corr $\left[e_{\xi}(j, x\right.$, men, $t), e_{\xi}(j, x$, women, $\left.t)\right]$ as 0.68 , assuming independence of age and household position. The correlation between neighbouring five-year age groups was 0.65 based on an AR(1) model across age groups, assuming independence across sex and household position. In other words, writing $\xi(j, x, s, t)$ as $\xi(j)$ for simplicity, the AR(1) model that we assumed implies that $\xi(j)=\beta \xi(j-1)+u(j),|\beta|<1$, where the coefficient $\beta$ equals the correlation between $\xi(j)$ and $\xi(j-1)$, while the residual $u(j)$ has expectation zero and variance that is independent of age $j$.

\section{Selected results}

We simulated 3000 sample paths of the four random walks defined in the previous section, assuming a normal distribution of the $\varepsilon(j, t)$-terms with zero expectations and variances as estimated, added logit transformed point predictions $\hat{\xi}(1, x, s, t)=\ln \{\hat{\rho}(1, x, s, t) /[1-\hat{\rho}(1, x, s, t)]\}$ from the updated household forecast, transformed back to the $\rho$-scale, and applied the simulated shares to the simulated population numbers $W(x, s, t)$. The four shares cover all private household positions, except for "lone parent"; the latter share is found as one minus the sum of the four shares, for each combination of age, sex, and time. The 
shares relate to private households only. In contrast, the population numbers apply to all persons, both those in private and institutional households. This slightly exaggerates our household numbers. For the highest age group (age 90+) our results are not reliable, since 42 per cent of the women and 27 per cent of the men of that age live in an institution, according to the Census of 2001. At ages 80-84 the shares are ten and six per cent, respectively. Below age 70 the shares are below one per cent.

For illustration, we computed predictive distributions for the following variables.

1. The population $V(j, x, s, t)$ for men and women in age groups $20-24,50-54$, and 80-84; in 2010, 2020, and 2030; in positions "married", "living alone", "cohabiting", "child/other", and "lone parent".

2. The number of private households at 2010,2020, and 2030, for five household types. The numbers of cohabiting and married households were estimated as one half the total number of persons with that household position. The numbers of one-person and lone-parent households equal the numbers of persons with that household position. The number of other households was estimated as the number of persons with that position (that is, the number of persons with household position "child" or "other" who are 25 years or older) divided by 2.5 , which was the mean size in the 2002 wave of the SLC. We also computed the total number of private households as the sum of the five households.

3. Mean size of private households for 2010,2020, and 2030, computed as the total population $\sum_{j, x, s} V(j, x, s, t)$ divided by the number of private households.

In Tables 2 and 3 where relevant results are presented, we shall characterize forecast uncertainty by means of the coefficient of variation $(\mathrm{CV})$ and the high and low bounds of the 80 per cent prediction intervals for the variables concerned. Equivalently, we could have selected the bounds of one standard deviation or two standard deviation intervals, corresponding to about 68 and 95 per cent coverage probability, respectively. However, a coverage probability of 80 per cent has become customary in probabilistic demographic forecasts; see e.g. Alho and Spencer 2005, Chapter 11; Alho et al. 2006; Scherbov and Ediev 2007). The results that we shall present in the form of box and whisker plots have the usual first and third quartiles as the upper and lower borders of the boxes. The lines ("whiskers") show the largest or smallest predicted value that falls within a distance of 1.5 times the box size from the nearest border. The circles fall farther away - these are considered "extreme" values.

The number of private households is forecasted to grow by $28 \%$ in $2002-2030$, from 2.026 million to 2.587 million (Table 2). The population is expected to increase by $16 \%$ (not shown here), implying a drop in the mean size of private households from 2.21 to 2.04. The fraction of one-person households in 2030 is expected to be $40 \%$, up from 36\% in 2002. Married couple households and one-person households have the lowest relative forecast uncertainty as measured by the coefficient of variation. At the same time, these household types are the most numerous. The lower bound of the 80 per cent 
interval for the total number of households increases regularly, which indicates that the chance for a systematic decrease in that number is small. In fact, none of the 3000 simulations in any of the three years 2010, 2020, or 2030 show a number that is smaller than that in 2002 (see also Figure 7a to be discussed below). At the same time, the simulations imply an estimated chance of 12 per cent that there will be fewer married couple households in 2030 than there were in 2002 (chances are 20 per cent in 2010 and 15 per cent in 2020).

Table 2. Average value (in 1,000's), coefficient of variation (\%), and lower and upper bounds (in 1,000 's) of $80 \%$ prediction intervals, for the number of private households, by household type

\begin{tabular}{lcccccc}
\hline & $\begin{array}{c}\text { Married } \\
\text { couple }\end{array}$ & $\begin{array}{c}\text { One- } \\
\text { person } \\
\text { household }\end{array}$ & $\begin{array}{c}\text { Cohabiting } \\
\text { couple }\end{array}$ & $\begin{array}{c}\text { Lone- } \\
\text { parent } \\
\text { household }\end{array}$ & $\begin{array}{c}\text { Other } \\
\text { private } \\
\text { household }\end{array}$ & $\begin{array}{c}\text { All private } \\
\text { households }\end{array}$ \\
\hline 2002 & 834 & 749 & 204 & 163 & 75 & 2,026 \\
& & & & & & \\
Average & 877 & 828 & 267 & 184 & 42 & 2,198 \\
CV & 4.2 & 7.8 & 10.8 & 17.2 & 21.7 & 1.9 \\
$80 \%$ low & 831 & 745 & 231 & 144 & 31 & 2,146 \\
$80 \%$ high & 923 & 912 & 305 & 225 & 54 & 2,251 \\
& & & & & & \\
2020 & & & & & & \\
Average & 919 & 926 & 318 & 200 & 37 & 2,400 \\
CV & 6.8 & 11.7 & 15.0 & 24.6 & 34.8 & 3.5 \\
$80 \%$ low & 840 & 791 & 258 & 141 & 22 & 2,293 \\
$80 \%$ high & 1,000 & 1,068 & 380 & 264 & 54 & 2,509 \\
& & & & & & \\
2030 & & & & & & \\
Average & 956 & 1,044 & 345 & 207 & 36 & 2,587 \\
CV & 9.3 & 14.2 & 18.1 & 29.7 & 45.1 & 5.2 \\
$80 \%$ low & 842 & 863 & 266 & 134 & 18 & 2,418 \\
$80 \%$ high & 1,069 & 1,242 & 428 & 288 & 58 & 2,759 \\
\hline
\end{tabular}

Figures 7a-e illustrate these predictive distributions graphically in the form of box and whisker plots based on the 3,000 simulated values. The vertical scales for the five figures are the same, so that uncertainty can be compared between household types. Whereas Table 2 shows modest relative uncertainty for one-person households (as measured by the CV), the fact that these households are so numerous implies that absolute uncertainty is largest for this household type, cf. the heights of the boxes.

Table 3 shows the coefficient of variation for the number of men and women in different household positions, for selected age groups. The level of uncertainty is directly related to the variance of the $\varepsilon(j, t)$-terms of the random walk, but this effect is mediated by the point prediction. For instance, married men and women had low values for these variances, but in the 20-24 age group, where their shares are low, the $\mathrm{CV}$ is high. In this age group, household position CHLD/OTHR (in practice 
"child") has the lowest uncertainty among the five household positions. In the 80-84 age group men are likely to live with their spouses (household position MAR), while women frequently live alone (SIN0), which results in low CV's. These differences are illustrated by the box and whisker plots for shares in Figures $8 \mathrm{a}$ and $8 \mathrm{~b}$.

Table 3. Coefficient of variation for predictive distributions of men and women by age and household position, in 2010, 2020, and 2030

\begin{tabular}{lcccccc}
\hline & $20-24$ & $50-54$ & $80-84$ & $20-24$ & $50-54$ & $80-84$ \\
\hline 2010 & & Men & & & Women & \\
MAR & 0.312 & 0.072 & 0.069 & 0.300 & 0.071 & 0.166 \\
SIN0 & 0.167 & 0.217 & 0.223 & 0.178 & 0.230 & 0.110 \\
COH & 0.321 & 0.288 & 0.292 & 0.256 & 0.280 & 0.341 \\
CHLD/OTHR & 0.106 & 0.711 & 0.323 & 0.150 & 1.051 & 0.283 \\
SIN+ & 1.139 & 0.331 & 1.252 & 0.969 & 0.258 & 1.213 \\
& & & & & & \\
2020 & & & & & & \\
MAR & 0.489 & 0.113 & 0.128 & 0.466 & 0.113 & 0.224 \\
SIN0 & 0.246 & 0.312 & 0.337 & 0.261 & 0.347 & 0.194 \\
COH & 0.453 & 0.415 & 0.389 & 0.358 & 0.409 & 0.440 \\
CHLD/OTHR & 0.163 & 1.585 & 0.626 & 2.000 & 0.374 & 1.857 \\
SIN+ & 2.093 & 0.429 & 2.176 & & & \\
& & & & & & \\
2030 & & & & 0.602 & 0.152 & 0.280 \\
MAR & 0.611 & 0.160 & 0.205 & 0.329 & 0.417 & 0.245 \\
SIN0 & 0.311 & 0.380 & 0.395 & 0.444 & 0.480 & 0.507 \\
COH & 0.559 & 0.494 & 0.489 & 0.290 & 2.465 & 0.962 \\
CHLD/OTHR & 0.218 & 1.969 & 0.878 & 2.252 & 0.479 & 1.748 \\
SIN+ & 2.822 & 0.540 & 2.368 & & & \\
\hline
\end{tabular}

Abbreviations for household positions: MAR: married, living with spouse; SIN0: living alone; $\mathrm{COH}$ : living in consensual union; CHLD/OTHR: child under 25 years of age living with parents, or adult living in other private household; SIN+: lone parent.

The results in Table 3 are based on the predictive distributions for numbers of persons in various household positions. It is instructive to analyse whether the uncertainty in those predictions derives mainly from that in the predictions for the shares $\rho$, or from the predictions for the population numbers $W$. Write the number of persons in a given household position, for a certain combination of age, sex, and time as $V=\rho W$ for short. Its coefficient of variation is $\operatorname{CV}(V)=\operatorname{Var}(V)^{1 / 2} / \mathrm{E}[V]$. Since $\rho$ and $W$ are assumed independent (see Section 5 for a discussion), $\mathrm{E}[V]=\mathrm{E}[\rho] \mathrm{E}[W]$. Using the formula for conditional variances, $\operatorname{Var}(V)=\mathrm{E}[\operatorname{Var}(V \mid \rho)]+\operatorname{Var}(\mathrm{E}[V \mid \rho])=\mathrm{E}\left[\rho^{2}\right] \operatorname{Var}(W)+\mathrm{E}[W]^{2} \operatorname{Var}(\rho)$. This leads, after some manipulations to the formula

$$
\mathrm{CV}^{2}(V)=\mathrm{CV}^{2}(\rho)+\mathrm{CV}^{2}(W)+\mathrm{CV}^{2}(\rho) \mathrm{CV}^{2}(W)
$$


Consider, e.g, married women in age 50-54, in 2030. Estimated values of $\mathrm{CV}^{2}(\rho)$ and $\mathrm{CV}^{2}(W)$ are 0.0213 and 0.0018 , respectively (not shown here). Plugging in these values in the right-hand side of the equality, we get $0.0213+0.0018+0.0213 \times 0.0018=0.0231$ for $\mathrm{CV}^{2}(V)$; compare the $\mathrm{CV}(V)$-value of 0.152 in Table 3 . Hence the uncertainty in $V$, as expressed by the coefficient of variation, derives almost entirely from that of the share $\rho$. This holds fairly generally for the age-groups that were already born at jump-off time. However, in the oldest ages the uncertainty of forecasting mortality is an important factor of uncertainty. For instance, men aged 80-84 in 2030 have a CV equal to 0.1456 , while the $\mathrm{CV}$ for the married share is 0.1424 . Thus, both sources contribute almost evenly to the CV of the number of married men that is given as 0.205 in Table 3 .

\section{Summary and concluding remarks}

We have developed a method for computing probabilistic household forecasts, and applied it to data from Norway. The method combines a probabilistic population forecast with a probabilistic forecast for the shares of persons in six household positions, by age and sex. Conceptual difficulties in defining household positions appear to have an impact on the quality of the basic data. Thus, empirical estimates based on Norwegian survey data differed markedly from the census estimates that were obtained for essentially the same point in time. In this work we primarily relied on the Norwegian census, because it appeared to be more consistent with the earlier forecast we used in error estimation, and our work was primarily motivated by the economic implications of household structure. However, it is clear that for other applications of household data changing perceptions of one's position may be of equal interest. Such forecasts would be expected to be more uncertain.

Point predictions for the shares were obtained from the multi-state LIPRO model. The transition probabilities estimated around year 2000 imply a continued increase in the number of single-person households.

Uncertainty parameters were estimated from observed errors of an old household forecast against a subsequent census. Our preferred model for the shares relied on an empirically defined hierarchical model of continued fractions. We also experimented with the direct modelling of the shares, but found (details not shown) that the resulting predictive distributions for the shares had much larger error variances. It is important to exercise care in the stochastic modelling of the shares.

We find that the coefficient of variation in future numbers of married couples, cohabiting couples, and one-person households is lower than that for lone parents and other private households. Moreover, for most ages and most household positions, it is the uncertainty of the share, rather than the uncertainty of the base population that determines the uncertainty of the number of individuals in different household positions. 
There are various sources of uncertainty that have an impact on our results. The deterministic population model and the deterministic household model are both of the book-keeping type. Hence they will result in perfectly accurate forecasts, once the parameter values are selected correctly. For LIPRO this is true insofar as we mean by parameter values those that follow implicitly from the consistency adjustments. Observed errors in the household shares come from wrong assumptions in the old deterministic household forecast and errors in the census data. It is reasonable to assume that the assumptions of the old household forecast have a bigger impact than the errors in the census data (although the latter error source may be considerable for shares of children aged 20-24, who live in the parental household). The variation in the results of the probabilistic household forecast comes from several sources: (i) estimated (co-)variances in the parameters for fertility, mortality, and migration in the population model; (ii) assumptions about the way these (co-)variances propagate over time through the age structure; (iii) estimated (co-)variances in household shares; (iv) the assumed random walk model for these shares. Our approach excludes other sources of uncertainty. In particular, there is no covariance between population variables and household variables, due to our implicit assumption of independence. The latter point can be clarified as follows.

We have simulated random shares that allocate persons over various household positions. The shares were combined with random population numbers from an existing stochastic population forecast. This approach implicitly assumes independence between the population numbers (and the underlying processes of birth, death, and migration) and the shares (and the underlying processes of household formation and dissolution). In reality, the two types of variable are not necessarily independent. For instance, mortality is most likely correlated with the chance to live alone - in particular for the elderly, through widowhood. Other things being equal, when there are many elderly men (for instance due to low mortality), the share of elderly women who live alone is likely low, and vice versa. However, correlations of this and similar kinds are likely to have only limited numerical importance. Intuitively, this is because first, the uncertainty in population sizes for the elderly, and hence in survival, is much less than that of the shares in most ages. Second, male survival and female survival have a high, positive correlation $(>0.80)$, so the difference in male and female survival has an even smaller uncertainty than the populations themselves.

A somewhat subtle problem in our stochastic formulation relates to the consistency constraints used in LIPRO. These are implemented by an iterative calculation, and it is not practicable to try to enforce them for all sample paths, that numbered 3,000 in our application. We investigated the possibility that increasing correlation between male and female shares might reduce any discrepancy. The results in the Appendix confirm that this is the case. 
A basic difficulty in the modelling of the household position data derives from the fact that households are viewed as characteristics of the individuals. This approach has been adopted on grounds of conceptual simplicity. Individuals enter and leave the household, and this changes its structure and type. However, since the behaviour of two individuals may be linked, we are confronted with the socalled two-sex problem, for instance in the case of couple formation. A challenging future direction is the development of a richer population model that includes actual households as units of observation.

The data requirements for our approach are not very strong. Therefore, the method that we report here can also be applied to other countries. First, a probabilistic forecast of the population by sex and age is required. The approaches developed in the past to compute such forecasts have been applied to numerous countries - most of these in the Western world (cf. the examples mentioned in Section 1), but not exclusively. See Booth (2006) for a review of methods. Second, point predictions and uncertainty measures are required for the random shares that distribute the population over several household positions. The point predictions can be derived from any household forecast model that predicts the population broken down by age, sex, and household position. We have used LIPRO, which requires data on household events, among others. Other models which demand less detailed data have been employed elsewhere (e.g. ProFamy; see Zeng et al. 2007, or the method developed by Statistics Netherlands, see Alders and Manting 1998). We estimated uncertainty parameters for the shares from the errors in an old household forecast. Those errors require observed data on household shares by age and sex, and an old forecast for those shares. Population data with information on age, sex, and household position from the 2000 round of population censuses in EU member countries are available from Eurostat. Similar data should exist for other countries as well, because the United Nations Economic Commission for Europe recommended including this type of information in the set of tables each member country should produce in the 2000 round of population censuses (United Nations Economic Commission for Europe 1998). Thus it should be possible to evaluate household forecasts made before 2000 for the countries where such forecasts have been computed. If they do not exist, error estimates can be borrowed from other countries. Of course, whenever time series of past estimates of shares are available, error estimates can be derived directly from the statistical modelling of such series.

The method in which random shares are combined with random numbers for the population is not restricted to the particular example in this paper. A similar method could be applied to probabilistic forecasts for other divisions of the population, such as household size, health or disability status, region of residence, labour market status, etc. For instance, Scherbov and Ediev (2007) apply random headship rates (i.e. the share of the population that is head of a household) to a probabilistic population forecast. Their headship rates are specific for household size, and thus the authors are able to predict households by size. Also, statistical agencies of many countries compute regional forecasts on a regular 
basis. The errors in historical regional forecasts can be analysed, modelled, and predicted. Combined with regional shares in the current regional forecast those errors give random regional shares, which, in turn, can be applied to a probabilistic population forecast.

\section{Acknowledgement}

Part of this project was carried out when the authors participated in the international research group "Changing family patterns in Norway and other industrialized countries" at the Centre for Advanced Study, the Norwegian Academy of Science and Letters, Oslo, during the academic year 2006/2007. Øystein Kravdal kindly supplied us with deaths and exposure times by marital status, age, and sex for the years 1995-99. We also gratefully acknowledge useful comments received from two reviewers and the editors of the journal.

\section{References}

Alders, M. (1999) Stochastische huishoudensprognose 1998-2050 ("Stochastic household forecast 1998-2050"). Maandstatistiek van de Bevolking 11, 25-34.

Alders, M. (2001) Huishoudensprognose 2000-2050: Veronderstellingen over onzekerheidsmarges ("Household forecast 2000-2050: Assumptions on uncertainty intervals"). Maandstatistiek van de Bevolking 8, 14-17.

Alders, M. and Manting, D. (1998) Household scenarios for the European Union. Maandstatistiek van de Bevolking 10, 11-27.

Alders, M., Keilman, N. and Cruijsen, H. (2007) Assumptions for long-term stochastic population forecasts in 18 European countries. European Journal of Population 23, 33-69.

Alho, J. M. (1998) A stochastic forecast of the population of Finland. Reviews 1998/4. Helsinki: Statistics Finland.

Alho, J. and Spencer, B. (2005) Statistical Demography and Forecasting. New York: Springer.

Alho, J.M., Alders, M., Cruijsen, H., Keilman, N., Nikander, T. and Pham, D.Q. (2006) New forecast: Population decline postponed in Europe. Statistical Journal of the United Nations ECE 23, 1-10.

Alho, J., Cruijsen, H. and Keilman, N. (2008) Empirically based specification of forecast uncertainty. In Uncertain Demographics and Fiscal Sustainability (eds J. Alho, S. Hougaard Jensen, and J. Lassila) pp. 34-54. Cambridge: Cambridge University Press.

Booth, H. (2006) Demographic forecasting: 1980 to 2050 in review. International Journal of Forecasting 22, 547-581.

Conference of European Statisticians (2006) Recommendations for the 2010 Censuses of Population and Housing. Geneva: United Nations. 
De Beer, J. and Alders, M. (1999) Probabilistic population and household forecasts for the Netherlands. Working Paper nr. 45, Joint ECE-Eurostat Work Session on Demographic Projections, Perugia, Italy, 3-7 May 19999.

Glaser, K., Grundy, E. and Lynch, K. (2003) Transitions to supported environments in England and Wales among elderly widowed and divorced women: The changing balance between co-residence with family and institutional care. Journal of Women and Aging 15, 107-126.

Grundy, E. (2001) Living arrangements and the health of older persons in developed countries. Population Bulletin of the United Nations 42/43, 311-329.

Hoffmann-Nowotny, H.J. (1987) The future of the family. In Plenaries of the European Population Conference pp. 113-200. Helsinki: IUSSP/Central Statistical Office of Finland.

Holmberg, I. (1987) Household change and housing needs: A forecasting model. In Family Demography - Methods and Their Application (eds J. Bongaarts, T. Burch, and K. Wachter ) pp. 327341. Oxford: Clarendon Press

Jiang, L. and O’Neill, B. (2004) Toward a new model for probabilistic household forecasts. International Statistical Review 72, 51-64

Jiang, L. and O'Neill, B. (2006) Impacts of demographic events on US household change. Interim Report IR-06-030. Laxenburg: International Institute for Applied Systems Analysis.

Keilman, N., Kuijsten, A. and Vossen, A. eds. (1988) Modelling Household Formation and Dissolution. Oxford: Clarendon Press.

Keilman, N. and Brunborg, H. (1995) Household projections for Norway, 1990-2020. Report 95/21. Oslo: Statistics Norway.

Keilman, N. and Christiansen, S. (2008) Norwegian elderly less likely to live alone in the future. Submitted.

Keilman, N. and Keyfitz, N. (1988) Recurrent issues in dynamic household modelling. In Modelling Household Formation and Dissolution (eds N. Keilman, A. Kuijsten, and A. Vossen) pp. 254-285. Oxford: Clarendon Press.

Keilman, N., Pham, D.Q. and Hetland, A. (2002) Why population forecasts should be probabilistic illustrated by the case of Norway. Demographic Research 6, 15 May 2002, 409-454.

King, D. (1999) Official household projections in England: Methodology, usage and sensitivity tests. Working paper no. 47, Joint ECE-EUROSTAT Work Session on Demographic Projections, Perugia, Italy, May 3-7 1999.

Lee, R. (1999) Probabilistic approaches to population forecasting. In Rethinking Population Projections, A Supplement to Population and Development Review 24 (eds. W. Lutz, J. Vaupel, and D. Ahlburg), pp. 156-190.

Lee, R. and Tuljapurkar, S. (1994) Stochastic population forecasts for the United States: Beyond High, Medium, and Low. Journal of the American StatisticalAssociation 89, 1175-1189.

Lenoir R. (2007) The family as a social institution: struggles over legitimate representations of reality. In Symbolic Power in Cultural Contexts: Uncovering Social Reality (eds J. Houtsonen and A. Antikainen) pp. 31-41. Rotterdam: Sense Publishers. 
Lutz, W. and Scherbov, S. (1998) An expert-based framework for probabilistic national population projections: The example of Austria. European Journal of Population 14, 1-17.

Lutz, W., Sanderson, W. and Scherbov, S. (1996) Probabilistic population projections based on expert opinion. In The future population of the world: What can we assume today? (ed W. Lutz) pp. 397-428. London: Earthscan.

Lutz, W., Sanderson, W. and Scherbov, S. (2001) The end of world population growth. Nature 412, 543-545.

McMillan, D.B. and Herriott, R. (1985) Toward a longitudinal definition of households. Journal of Economic and Social Measurement 13: 349-360.

Meslé, F. (2004) Espérance de vie: Un avantage féminine menacé? Population et Sociétés 402, 1-4.

Moen, Ph. and Forest, K.B. (1999) Strengthening families: Policy issues for the twenty-first century. In Handbook of Marriage and the Family $2^{\text {nd }}$ edition (eds M.B. Sussman, S.K. Steinmetz, and G.W. Peterson ) pp. 633-663. New York: Plenum Press.

Muller, C., Gnanasekaran, K. and Knapp, K. (1999) Housing and Living Arrangements for the Elderly: An International Comparison Study. New York: International Longevity Center.

Normann, T. M. (2004) Samordnet levekårsundersøkelse 2002 - panelundersøkelsen ("Coordinated Survey on Living Conditions 2002 - Panel Survey"). Dokumentasjonsrapport. Oslo: Statistisk sentralbyrå (Notater 2004/55).

National Research Council - NRC (2000) Beyond six billion: Forecasting the world's population. Panel on Population Projections (eds John Bongaarts and Rodolfo Bulatao ). Committee on Population, Commission on Behavioral and Social Sciences and Education. Washington DC: National Academy Press.

O'Neill, B. and Chen, B. (2002) Demographic determinants of household energy use in the United States. In Population and Environment: Methods and Analysis, A Supplement to Population and Development Review 28 (eds W. Lutz, A. Prskawitz and W. Sanderson) pp. 53-88.

Scherbov, S. and Ediev, D. (2007) Probabilistic household projections based on an extension of headship rates method with application to the case of Russia. Working paper no. 16, Joint ECEEUROSTAT Work Session on Demographic Projections, Bucharest, 10-12 October 2007.

Schoen, R. (1988) Modeling Multigroup Populations. New York: Plenum Press.

Settles, B. (1999) The future of the families. In Handbook of Marriage and the Family $2^{\text {nd }}$ edition (eds M.B. Sussman, S.K. Steinmetz, and G.W. Peterson) pp. 143-175. New York: Plenum Press.

Smith, R.T. (1968) Family. I. Comparative Structure. In International Encyclopedia of the Social Sciences Volume 5 (ed D. Sills), pp. 301-313. New York: Mcmillan and Free Press.

Statistics Norway (2000) Social Trends 2000. Oslo: Statistics Norway (Statistical Analyses nr. 40).

Törnqvist, L. (1949). "Om de synspunkter, som bestämt valet av de primäre prognosantagendena" ("On the points of view that determined the choice of the main forecast assumptions"). In Beräkninger rörende Finlands befolkning, dess reproduktion och framtida utveckling (eds J. Hyppolä, A. Tunkelo, and L. Törnqvist) pp. 69-75. Statistiska Meddelanden nr. 38. Helsinki: Statistiska Centralbyrån (in Swedish and Finnish). 
United Nations (1973) Methods of Projecting Households and Families. Sales no. E.73.XIII.2. New York: United Nations.

United Nations Economic Commission for Europe (1998) Recommendations for the 2000 Censuses of Population and Housing. New York and Geneva: United Nations (Statistical Standards and Studies no. 49).

United States National Resources Planning Committee (1938) The Problems of a Changing Population. Washington D.C.: Government Printing Office.

Van Imhoff, E. (1992) A general characterization of consistency algorithms in multidimensional demographic projection models. Population Studies 46, 159-169.

Van Imhoff, E. and Keilman, N. (1991) LIPRO 2.0: An Application of a dynamic demographic projection model to household structure in The Netherlands. Amsterdam: Swets \& Zeitlinger.

Zeng, Y, Land, K. Wang, Z. and Gu, D. (2007) U.S. family household momentum and dynamics: An extension and application of the ProFamy method. Population Research and Policy Review 25: 1-41. 


\section{Appendix}

LIPRO enforces consistency restrictions for the point forecast, but this cannot be easily extended to the 3,000 simulation rounds. To see the effect of cross-sex correlation on lack of consistency regarding the number of marred and cohabiting couples, we increased the correlation from the reference value of 0.68 to 0.75 and 0.95 .

Table A. Average and standard deviation of the difference between the number of married and cohabiting men and women

\begin{tabular}{|c|c|c|c|c|c|c|}
\hline & \multicolumn{2}{|c|}{ Correlation 0.68} & \multicolumn{2}{|c|}{ Correlation 0.75} & \multicolumn{2}{|c|}{ Correlation 0.95} \\
\hline & Married & Cohabiting & Married & Cohabiting & Married & Cohabiting \\
\hline 2010 & & & & & & \\
\hline Average & $-11,023$ & 1,443 & $-10,992$ & 1,439 & $-10,883$ & 1,433 \\
\hline $\begin{array}{l}\text { Standard } \\
\text { deviation }\end{array}$ & 641 & 490 & 581 & 439 & 357 & 235 \\
\hline 2020 & & & & & & \\
\hline Average & $-19,000$ & $-3,140$ & $-18,933$ & $-3,241$ & $-18,672$ & $-3,623$ \\
\hline $\begin{array}{l}\text { Standard } \\
\text { deviation }\end{array}$ & 1,010 & 778 & 915 & 696 & 564 & 371 \\
\hline 2030 & & & & & & \\
\hline Average & $-31,902$ & 3,834 & $-31,775$ & 3,654 & $-31,302$ & 2,967 \\
\hline $\begin{array}{l}\text { Standard } \\
\text { deviation }\end{array}$ & 1,388 & 1,017 & 1,262 & 910 & 802 & 484 \\
\hline
\end{tabular}

An increase in correlation decreases the average difference marginally, and the standard deviation substantially. Differences between men and women increase with lead time, and the standard deviations indicate that the expected differences are significantly different from zero. Compared to the numbers in Table 2, the differences are small. 
Figure 1. Shares for 8 household positions

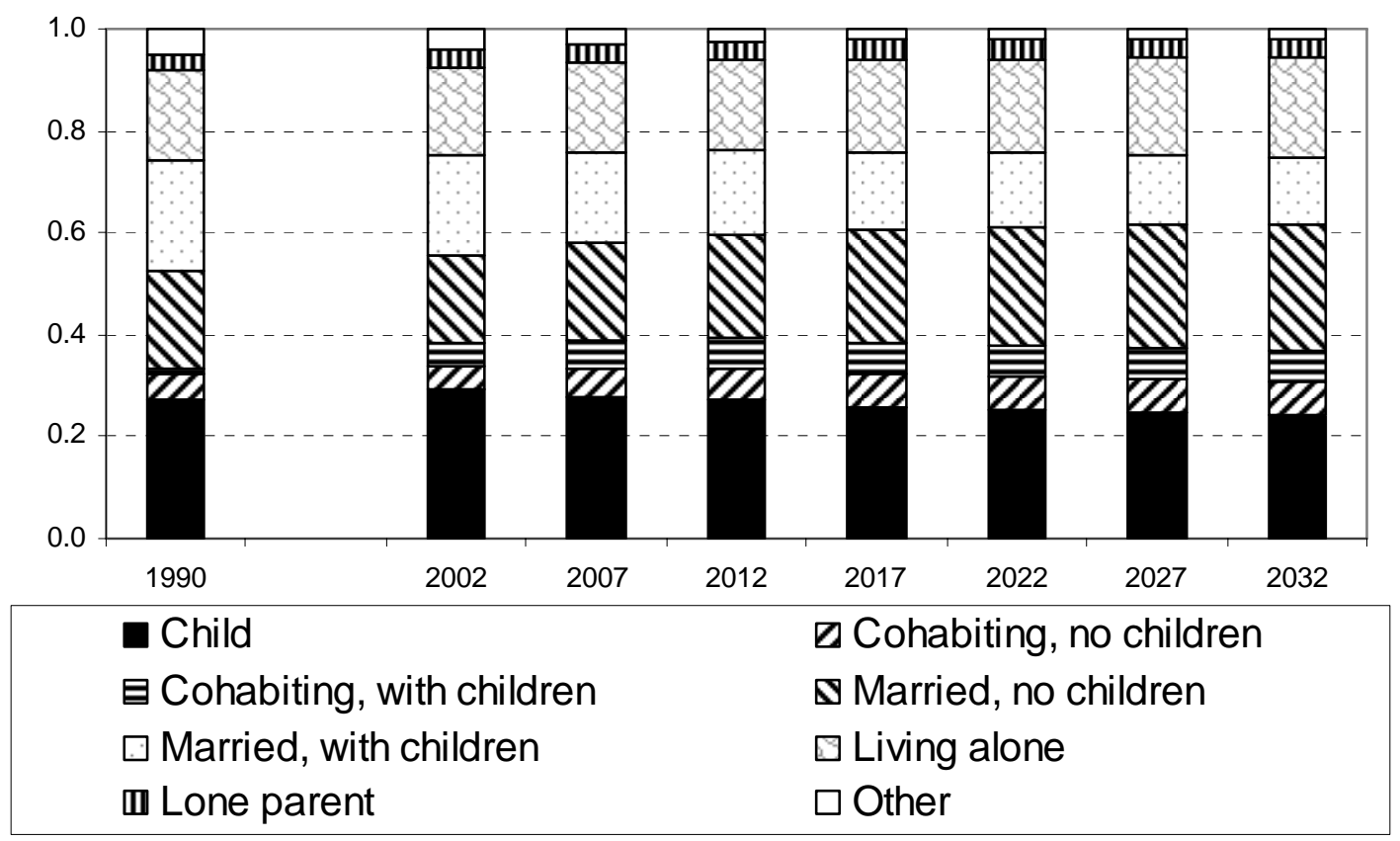


Figure 2. Proportion of women living alone

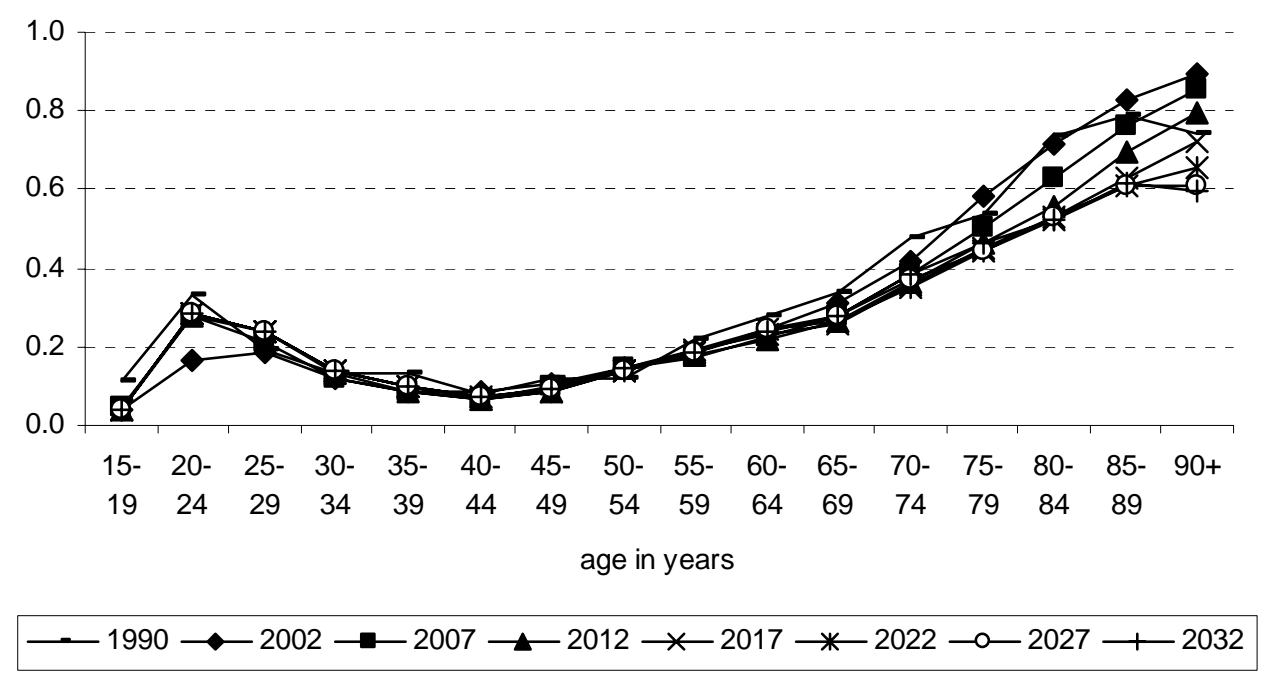

Figure 3. Proportion of women living with their spouse

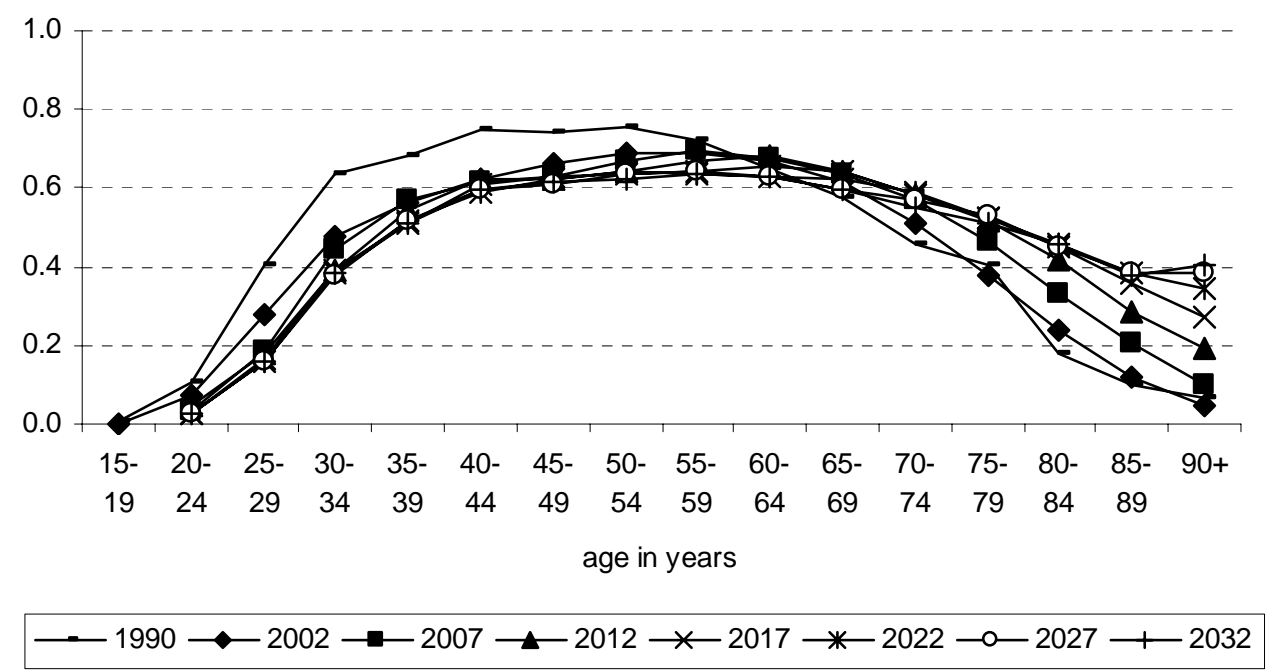


Figure 4. Observed and predicted shares for household position "cohabiting"
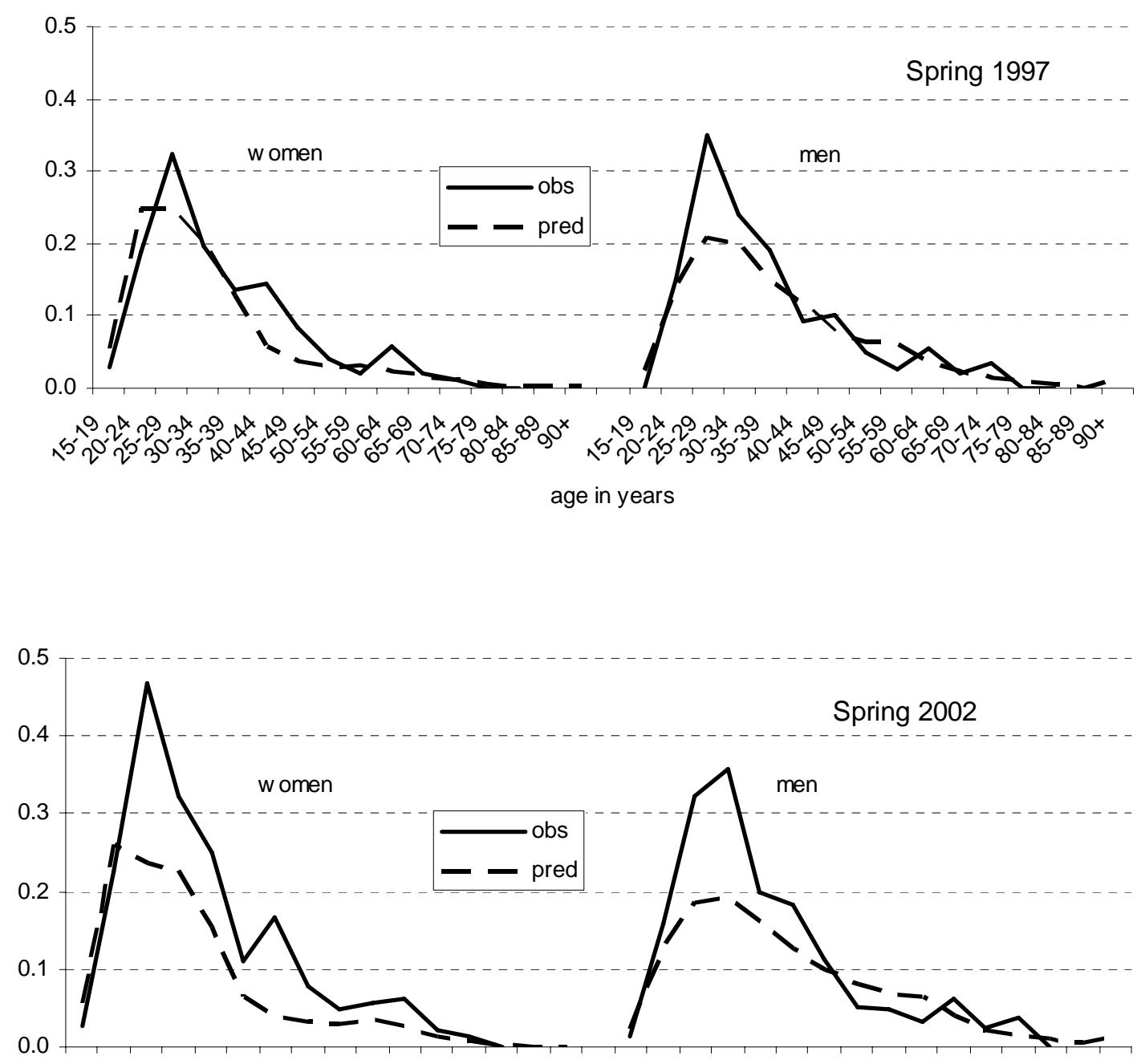

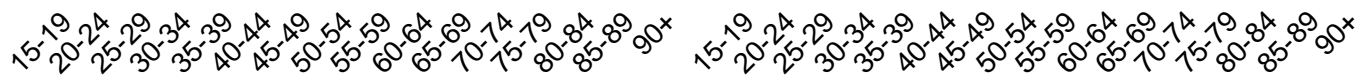

age in years

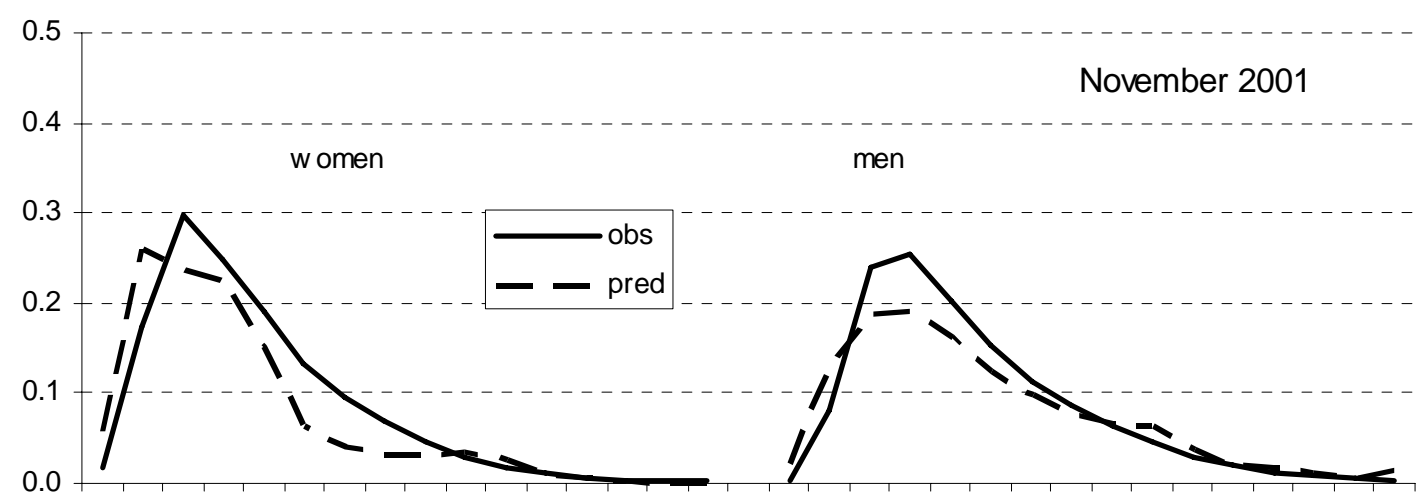

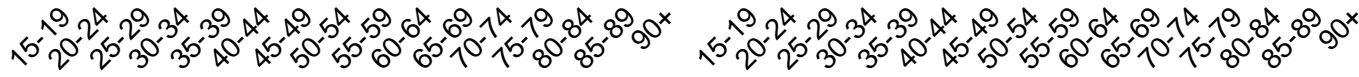

age in years 
Figure 5. Observed and predicted shares for household position "living with spouse"

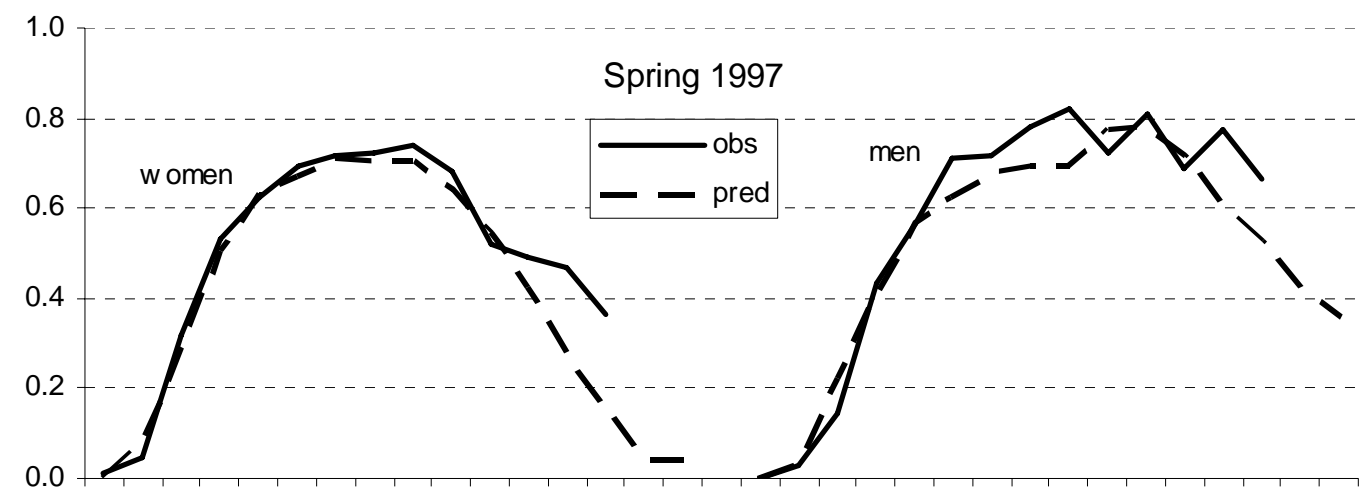

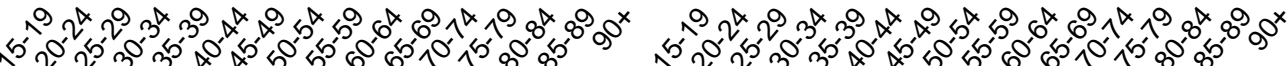

age in years

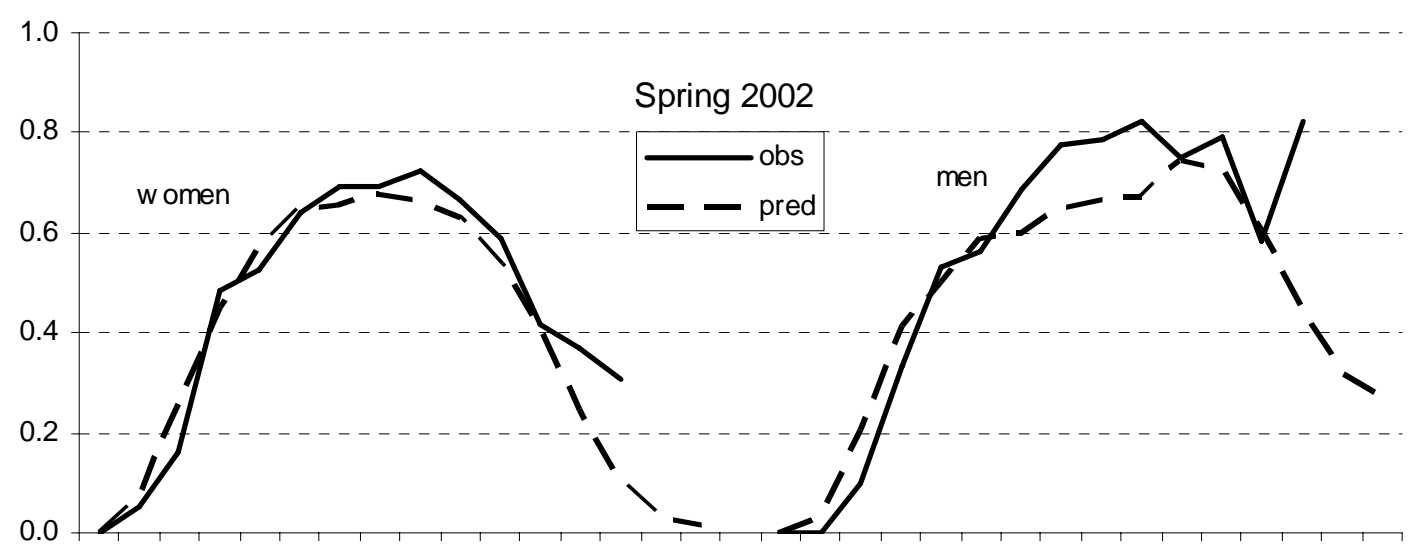

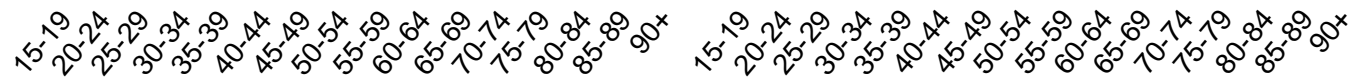

age in years

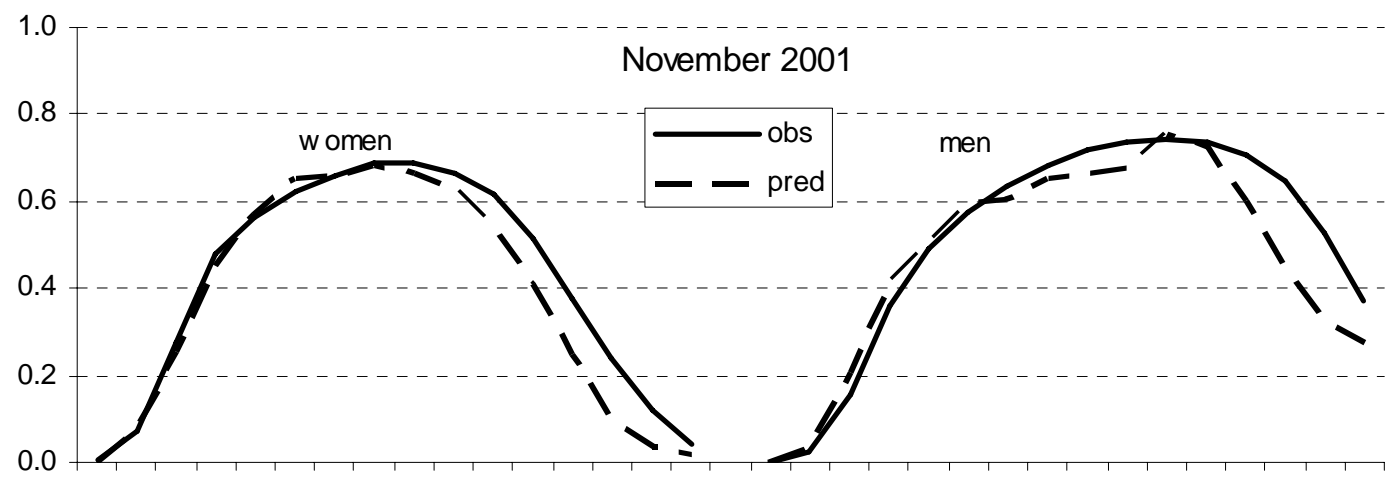

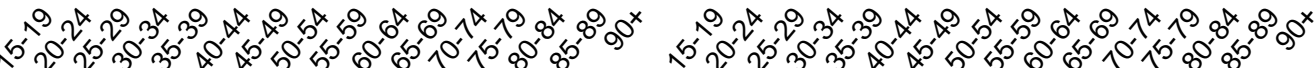

age in years 
Figure 6. Observed and predicted shares for household position "living alone"

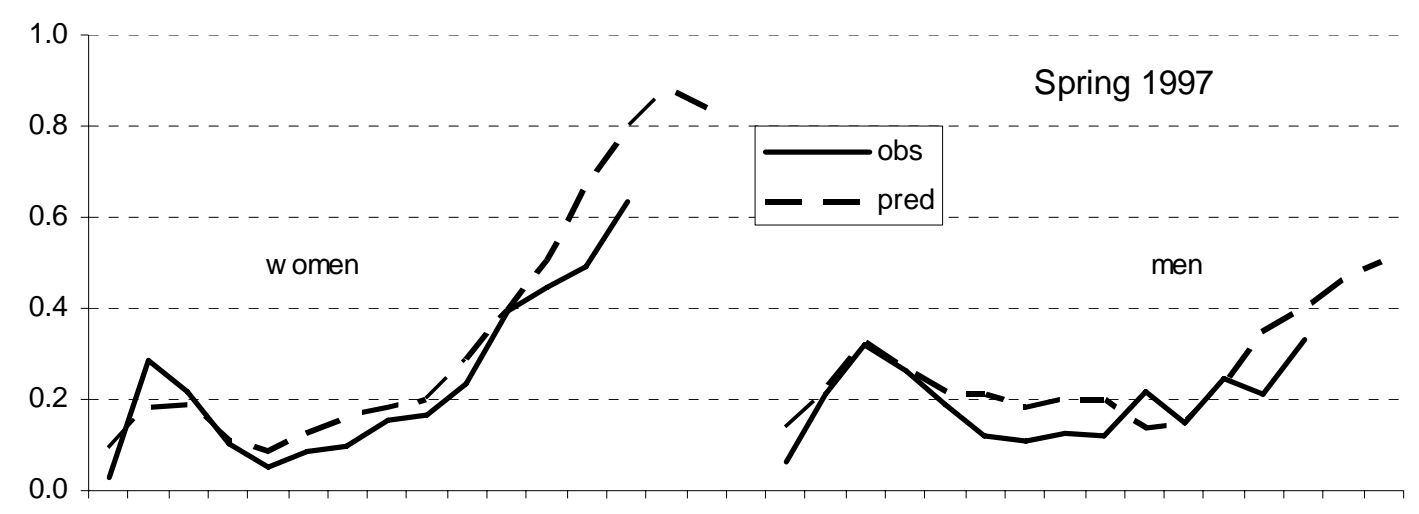

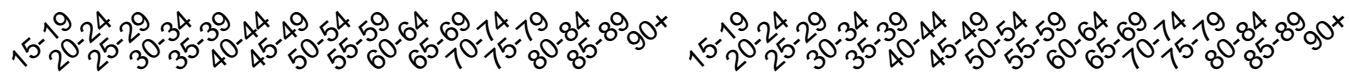

age in years

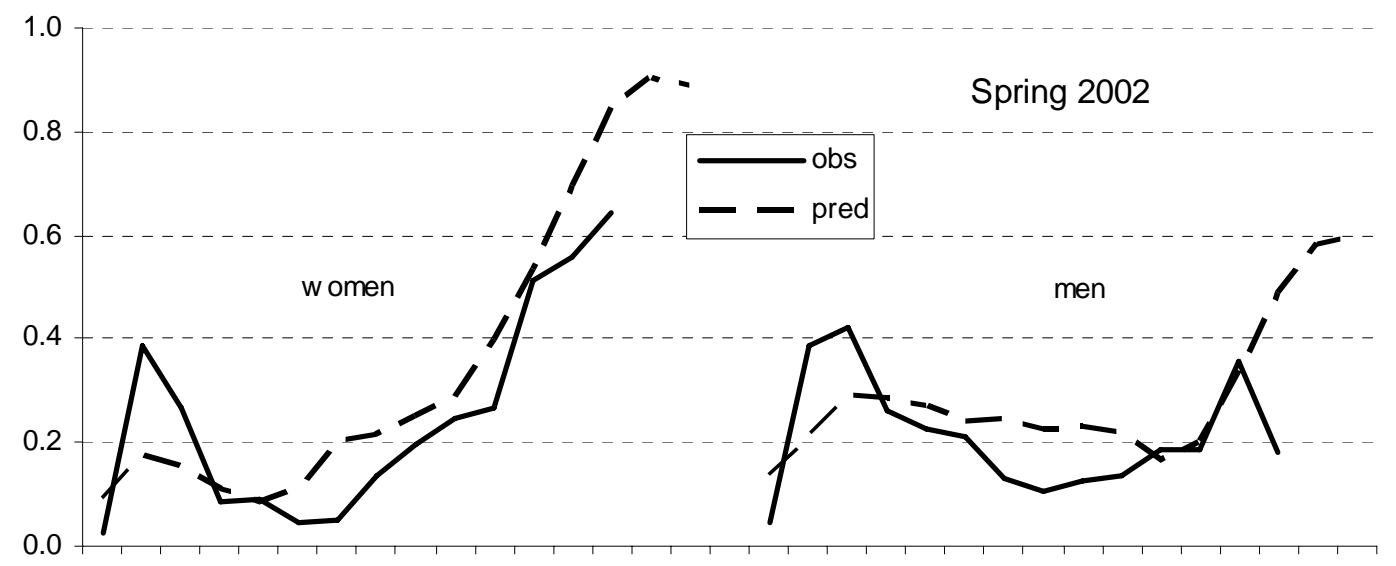

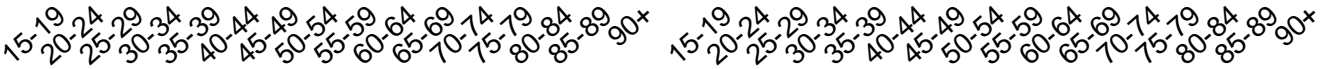

age in years

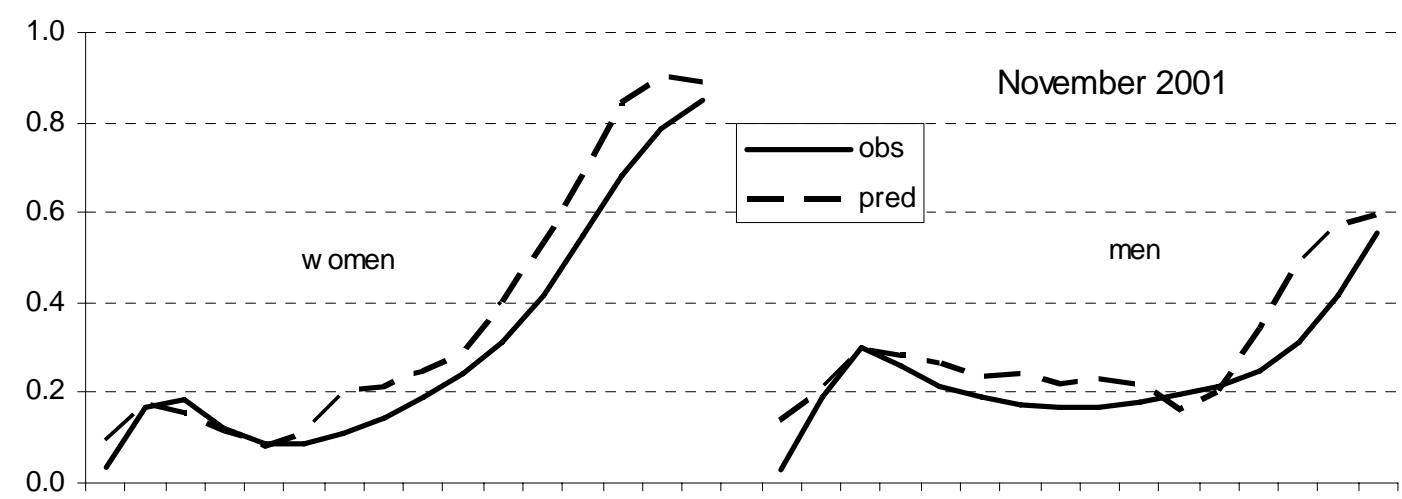

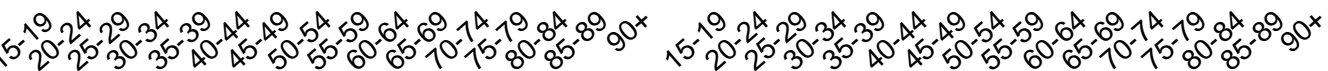

age in years 
Figure 7a-e. Box and whisker plots of predictive distributions of private households, 2002 (observed), 2010, 2020, 2030

a. The number of married-couple households

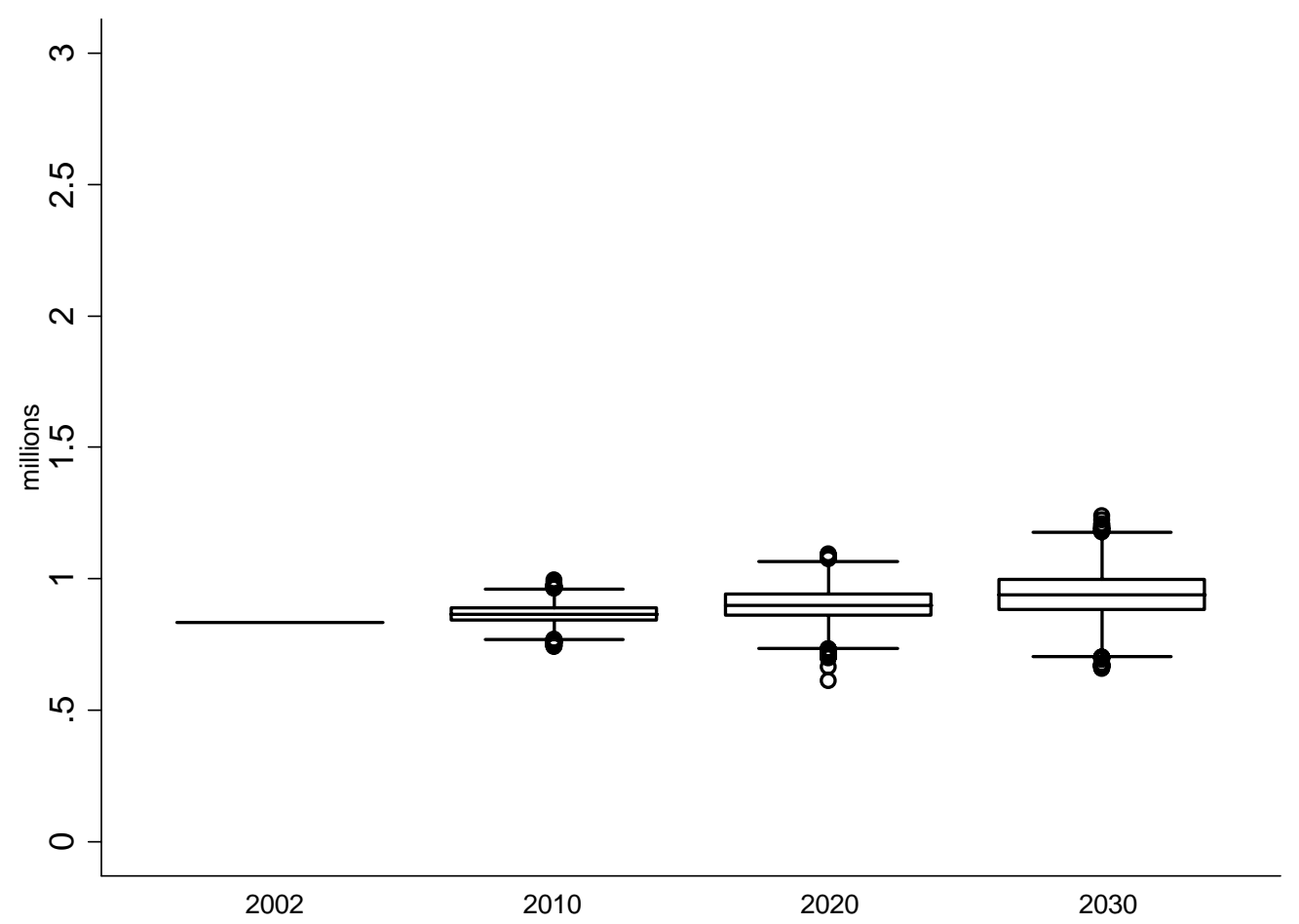

b. The number of one-person households

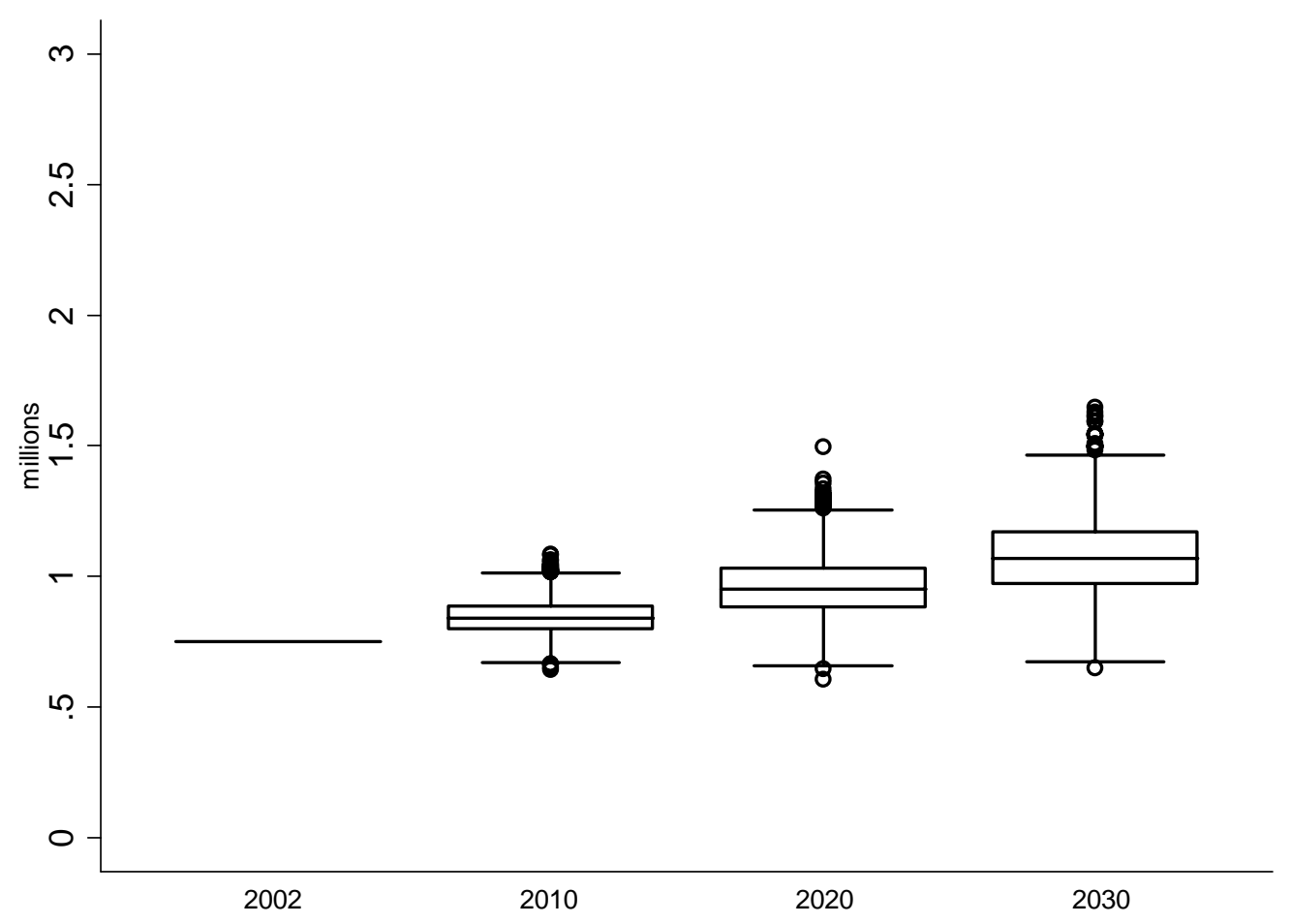


c. The number of cohabiting-couple households

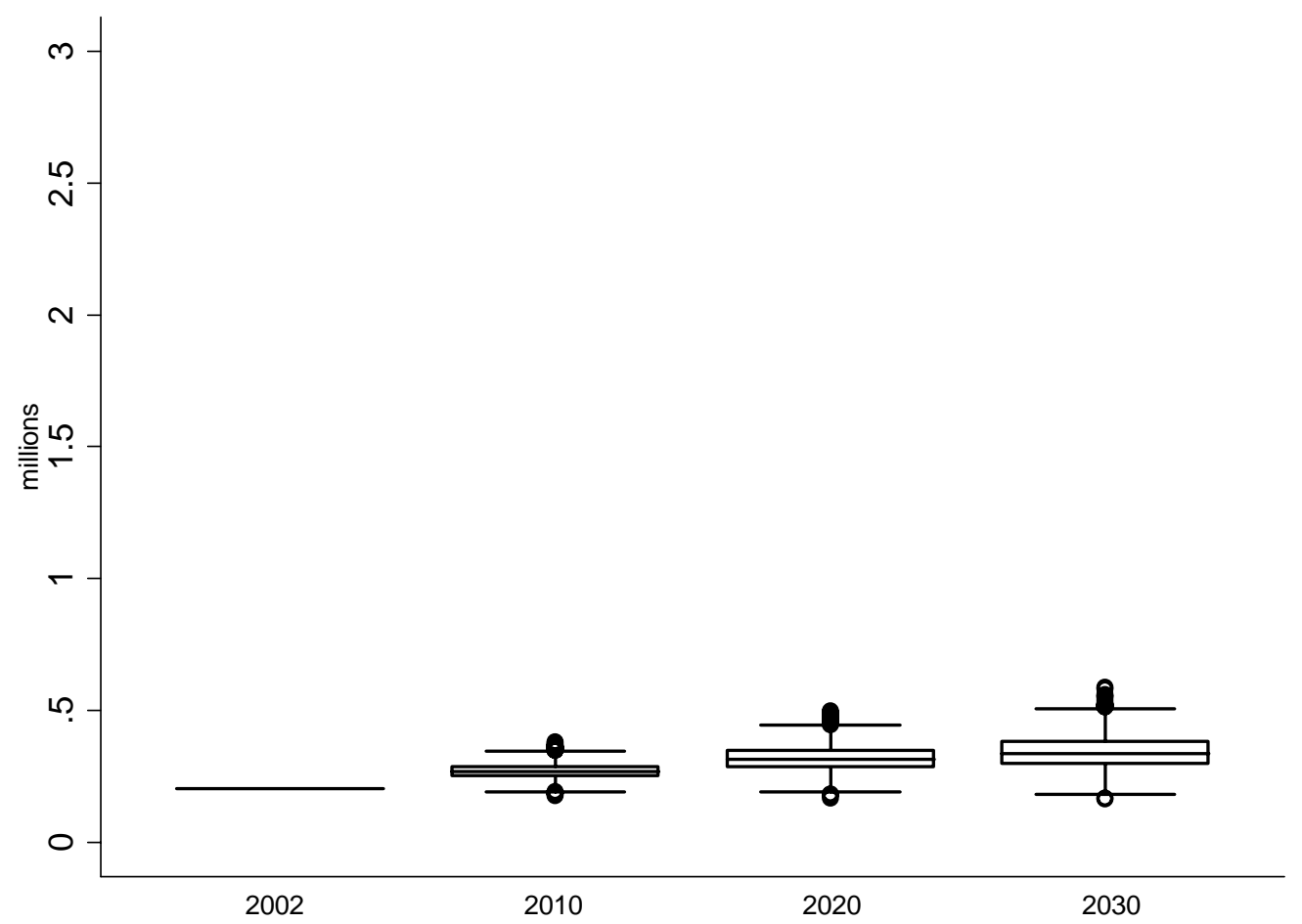

d. The number of lone-parent households

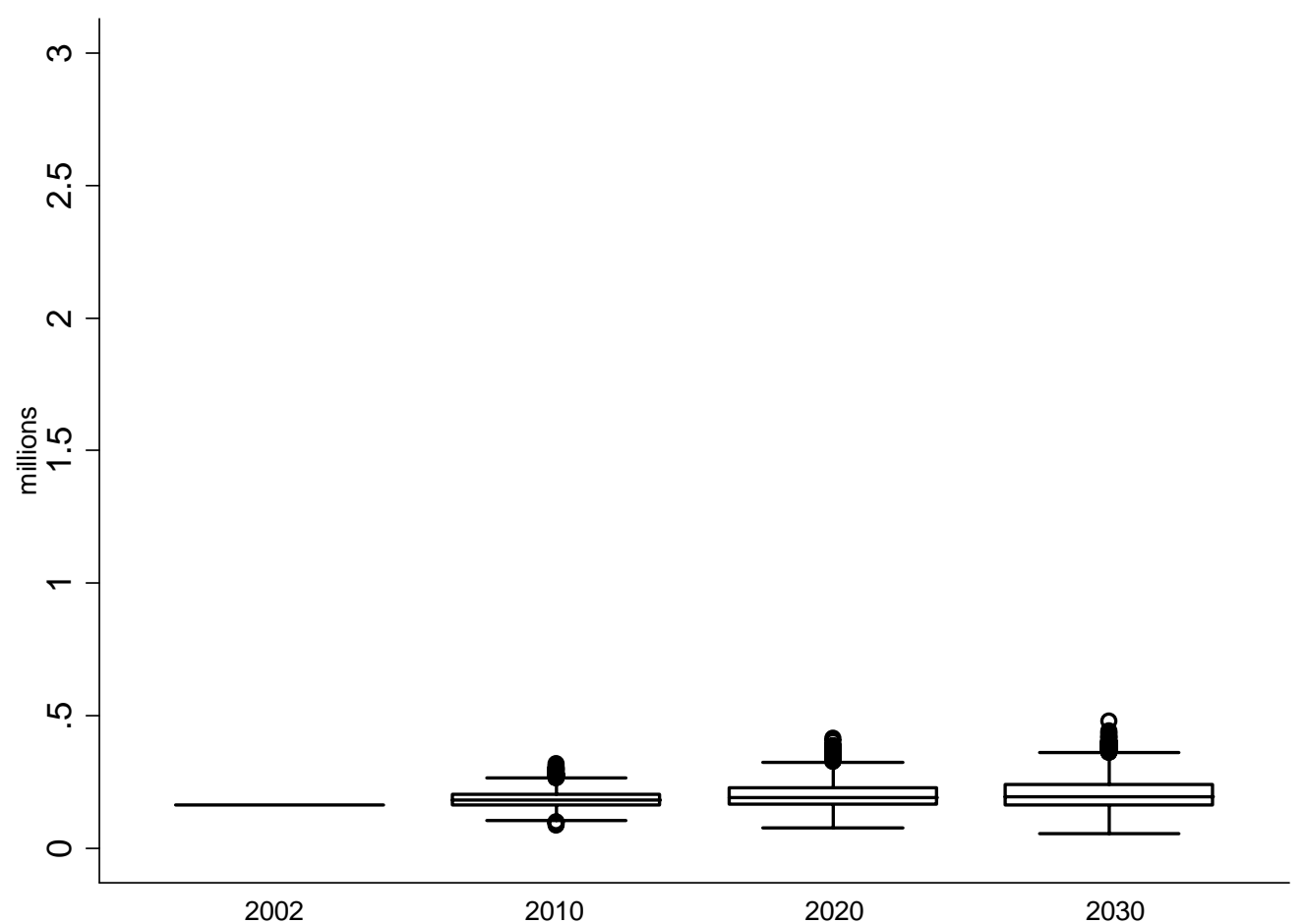


e. The number of all private households

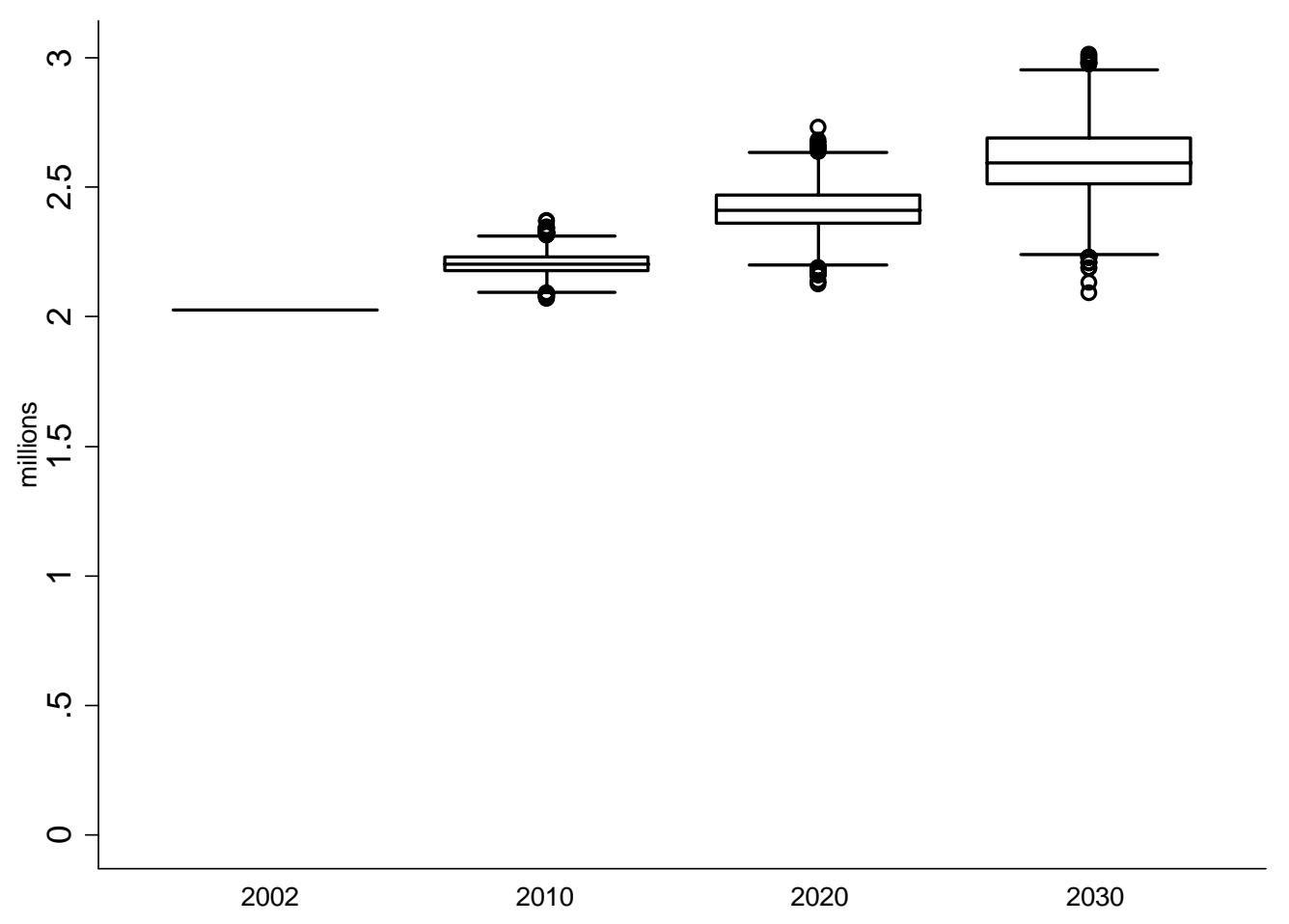


Figure 8a. Box and whisker plots for predictive distributions of shares "living with spouse" in 2030. Men and women in three age groups

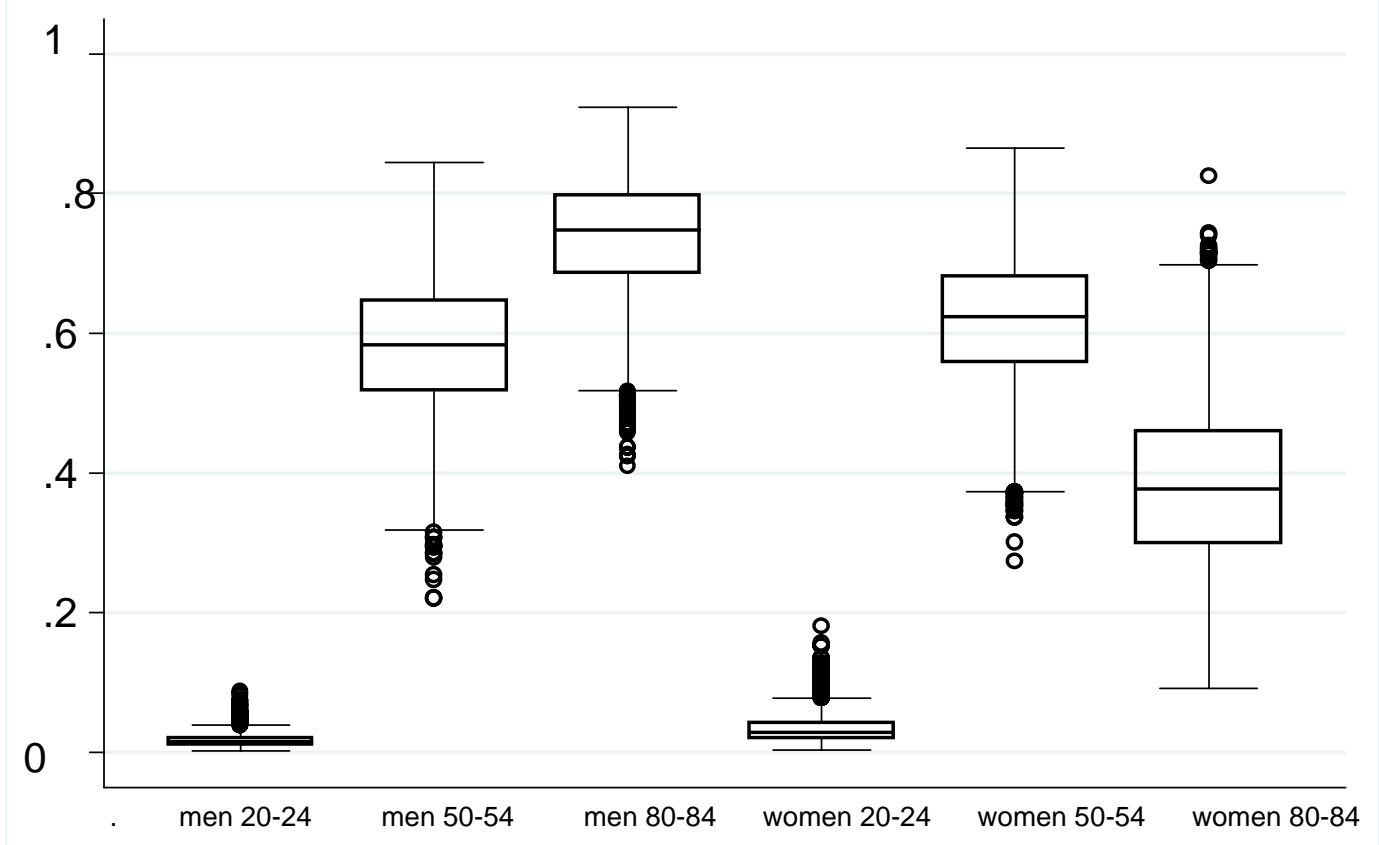

Figure 8b. Box and whisker plots for predictive distributions of shares "living alone" in 2030. Men and women in three age groups

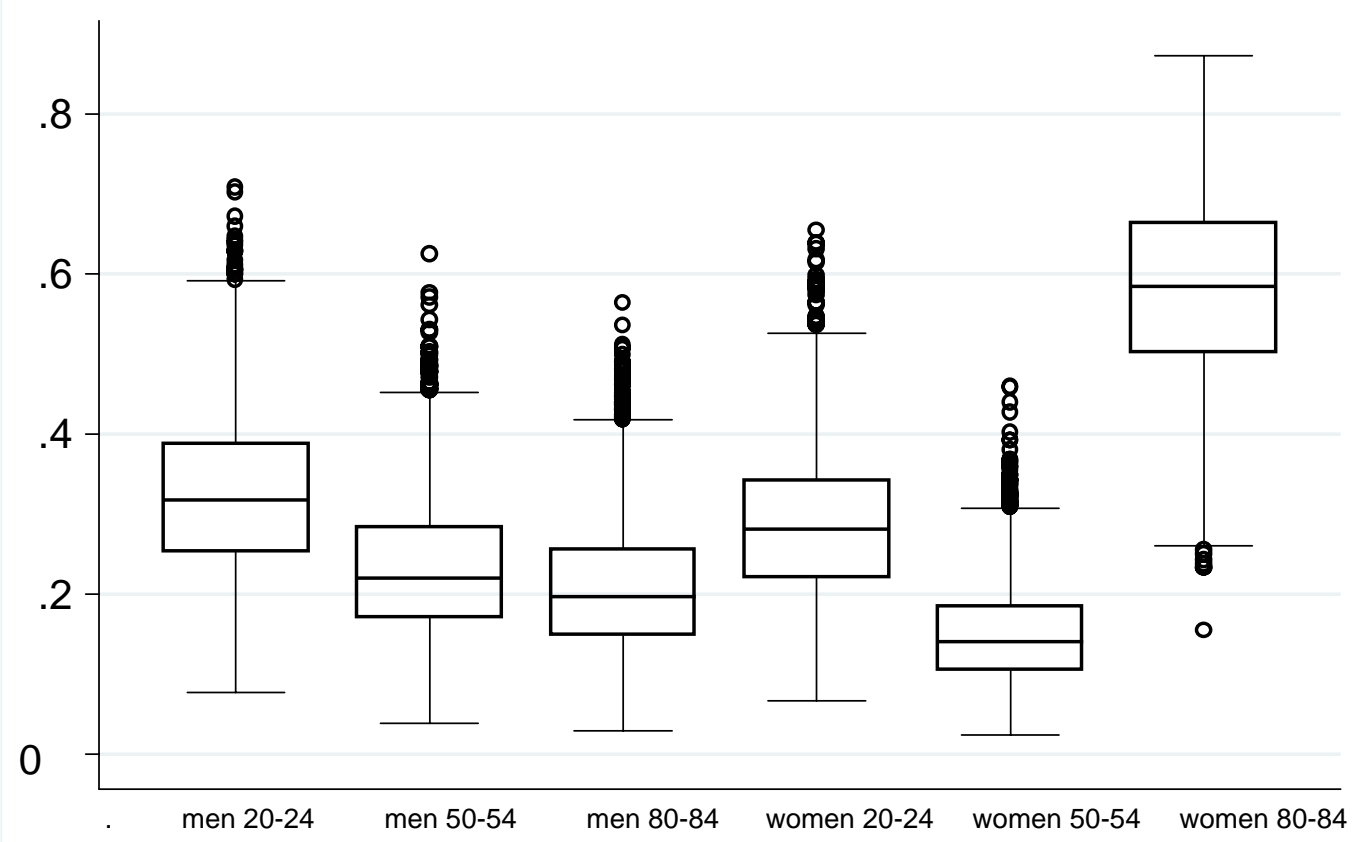

